\title{
Multidepot Recycling Vehicle Routing Problem with Resource Sharing and Time Window Assignment
}

\author{
Yong Wang $\mathbb{D},{ }^{1}$ Xiuwen Wang $\mathbb{D},{ }^{1}$ Xiangyang Guan $\mathbb{D}^{2},{ }^{2}$ and Jinjun Tang $\mathbb{D}^{3}$ \\ ${ }^{1}$ School of Economics and Management, Chongqing Jiaotong University, Chongqing 400074, China \\ ${ }^{2}$ Department of Civil and Environmental Engineering, University of Washington, Seattle, WA 98195, USA \\ ${ }^{3}$ Smart Transport Key Laboratory of Hunan Province, School of Traffic and Transportation Engineering, \\ Central South University, Changsha 410075, China \\ Correspondence should be addressed to Jinjun Tang; jinjuntang@csu.edu.cn
}

Received 8 April 2021; Revised 19 April 2021; Accepted 3 May 2021; Published 17 May 2021

Academic Editor: xinyuan chen

Copyright (C) 2021 Yong Wang et al. This is an open access article distributed under the Creative Commons Attribution License, which permits unrestricted use, distribution, and reproduction in any medium, provided the original work is properly cited.

\begin{abstract}
This study aims to provide tactical and operational decisions in multidepot recycling logistics networks with consideration of resource sharing (RS) and time window assignment (TWA) strategies. The RS strategy contributes to efficient resource allocation and utilization among recycling centers (RCs). The TWA strategy involves assigning time windows to customers to enhance the operational efficiency of logistics networks. A biobjective mathematical model is established to minimize the total operating cost and number of vehicles for solving the multidepot recycling vehicle routing problem with RS and TWA (MRVRPRSTWA). A hybrid heuristic algorithm including 3D $k$-means clustering algorithm and nondominated sorting genetic algorithm- (NSGA-) II (NSGA-II) is designed. The 3D $k$-means clustering algorithm groups customers into clusters on the basis of their spatial and temporal distances to reduce the computational complexity in optimizing the multidepot logistics networks. In comparison with NSGA algorithm, the NSGA-II algorithm incorporates an elitist strategy, which can improve the computational speed and robustness. In this study, the performance of the NSGA-II algorithm is compared with the other two algorithms. Results show that the proposed algorithm is superior in solving MRVRPRSTWA. The proposed model and algorithm are applied to an empirical case study in Chongqing City, China, to test their applicability in real logistics operations. Four different scenarios regarding whether the RS and TWA strategies are included or not are developed to test the efficacy of the proposed methods. The results indicate that the RS and TWA strategies can optimize the recycling services and resource allocation and utilization and enhance the operational efficiency, thus promoting the sustainable development of the logistics industry.
\end{abstract}

\section{Introduction}

Sustainability is a constant topic in the logistics industry and research $[1,2]$. In reverse logistics, recycling waste products can save resources and facilitate sustainable development [3]. Recycling vehicle routing problem (RVRP), one part of reverse logistics, often appears in logistics operations. For example, empty beer bottles are recycled at convenience stores. An increasing number of enterprises have begun to consider recycling products to improve the utilization of resources due to economic, legal, and social concerns $[4,5]$. Therefore, the growing demand for recycling services will stimulate the development of reverse logistics. The design, planning, and operation of sustainable reverse logistics systems pose a challenge to logistics organizations [6].

The low transportation resource utilization and irrational transport operations of logistics facilities still appear and need to be addressed [7, 8]. Resource sharing (RS) strategies have been proposed to optimize resource utilization and reduce operating cost in multidepot logistics networks [9]. Customers are reassigned to appropriate logistics facilities through these strategies to avoid unreasonable routing via customer information sharing [10]. Transportation resources are shared within and between logistics facilities to improve transportation resource utilization. Specifically, vehicles can be used to serve customers 
of a single logistics facility or customers of multiple logistics facilities many times when the time windows of customers allow [11]. In this study, the RS strategy is developed in the multidepot RVRP with time window (MRVRPTW) to optimize the resource utilization.

In traditional vehicle routing problems with time window (VRPTW), the service time windows for customers are obtained by the logistics service providers after negotiation with customers or are determined by customers $[12,13]$. Logistics service providers often recycle cargoes from customers at the same time every day [14]. In real life, the time windows for most customers are viewed as soft time windows, that is, they can be violated by paying certain penalties $[15,16]$. Most logistics service providers try to recycle cargoes within the predetermined time windows in logistics operations to reduce the penalty cost [17]. However, the vehicles cannot provide recycling services for customers in the expected time windows due to long transportation distance and unreasonable service time windows for logistics facilities $[18,19]$. Therefore, a set of candidate time windows are assigned to customers in this study, and recycling vehicle routes are designed on the basis of time window assignment (TWA) to optimize the operational efficiency and minimize the operating cost in multidepot RVRP with RS and TWA (MRVRPRSTWA).

In this study, the RS and TWA strategies are adopted to improve resource utilization, optimize resource allocation, and enhance the operational efficiency of multidepot recycling logistics networks. A bi-objective mathematical model is presented to obtain the minimum operating cost and the number of vehicles (TNV) in a multidepot logistics network with RS and TWA. A hybrid heuristic algorithm, including a 3D $k$-means clustering algorithm and nondominated sorting genetic algorithm- (NSGA-) II (NSGAII), is devised to optimize the recycling routes. The $3 \mathrm{D} k$ means clustering algorithm groups customers on the basis of their spatial and temporal distances to reduce the computational complexity. NSGA-II is used to assign time windows to customers and find the optimal solutions in the MRVRPRSTWA strategy. A real-world case study is performed to verify the applicability of MRVRPRSTWA in logistics operations. The results confirm the capability of the RS and TWA strategies in optimizing multidepot logistics networks.

The rest of this paper is organized as follows. In Section 2, relevant literature is reviewed. In Section 3, MRVRPRSTWA is described in detail. In Section 4, a multiobjective mathematical model is formulated to minimize the total operating cost and TNV. In Section 5, a hybrid heuristic algorithm is introduced to solve MRVRPRSTWA. In Section 6, a real-world case is presented to verify the applicability of the proposed method. In Section 7, the conclusions are drawn, and future research directions are proposed.

\section{Literature Review}

With the increasing attention on environmental protection, recycling and related problems have received great concern.
The RVRP with time window (RVRPTW) as the main form of reverse logistics has been widely studied to reduce the operating cost in recent years [20]. The multidepot RVRPTW (MRVRPTW) is developed to coordinate the recycling services among logistics facilities [21], and the RS strategy can be considered to optimize the resource utilization in MRVRPTW (MRVRPRSTW) [22]. Candidate time windows are assigned to customers via the TWA strategy to improve operational efficiency compared with the traditional time window in MRVRPRSTW [23]. MRVRPRSTW with TWA (MRVRPRSTWA) investigates the RS and TWA strategies to optimize the resource allocation and operational efficiency in multidepot logistics networks.

Increasing interest in recycled products and materials has led to a growing concern in recycling logistics [24, 25]. El korchi and Millet [26] investigated a framework, which used to generate and assess the reverse logistics channel structure, and proposed an environment-friendly structure with high economic benefits to optimize recycling services. Chan et al. [27] proposed a framework of reverse logistics on the basis of the value of reversed products, cost issue, and legislation perspective to optimize reverse logistics. Bai and Sarkis [28] introduced a flexible framework for reverse logistics and a performance measurement of third-party reverse logistics service provider model on the basis of a novel neighborhood rough set method to set the foundation for future research of reverse logistics. Roghanian and Pazhoheshfar [29] presented a probabilistic mixed liner programming model and genetic algorithm to minimize the total cost in reverse logistics. Shaik and Abdul-Kader [30] proposed a multi-criteria performance measurement model considering product lifecycle stages, strategies, capabilities, processes, perspectives, and measures to verify and enhance the enterprise's performance in reverse logistics.

The RS strategy, as a major issue, has drawn increasing attention on the enhanced resource utilization and reduced operating cost [31-33]. An et al. [34] constructed a network DEA model to calculate the cost of logistics network before and after RS and show the performance of the RS strategy. Sun et al. [35] analyzed and evaluated the effect of the RS strategy on alleviating or solving the traffic and environmental problems in megacities from five perspectives of resource, environment, convenience, economy, and governance. Quintero-Araujo et al. [36] investigated different collaborative scenarios on the basis of the RS strategy to obtain a lower logistics cost. The RS strategy is developed to minimize TNV and the total operating cost for improving the efficiency and sustainability of logistics networks [37]. Molina et al. [38] established a mathematical model that aims at maximizing the number of served customers and minimizing the total cost in the case of RS. Wang et al. [39] studied the RS strategy in multiple service periods and multidepot to enhance resource efficiency and refine the resource configuration.

Clustering algorithms are always used to group customers before determining vehicle routes in MDVRPTW to simplify the complexity of calculation [40, 41]. Min et al. [42] proposed the maximum-minimum distance clustering method to cluster customers in split-delivery VRP for the 
better performance of the algorithm. Ge et al. [43] added the service radius and load expansion factors to the clustering algorithm to avoid the vehicle overloading in MDVRPTW. Fan et al. [44] introduced a clustering algorithm based on the temporal-spatial distance to reduce the computational complexity and enhance the quality of initial solution in MDVRPTW. Liu et al. [45] investigated the clustering algorithm that groups customers in terms of the minimum distance and maximum demand to improve the efficiency of solving MDVRPTW.

Several algorithms are studied to improve the quality of solution in MRVRPTW [46-48]. Aras et al. [21] established two mixed-integer linear programming models and proposed a Tabu-search-based heuristic algorithm to solve MRVRPTW. Kim et al. [49] developed a two-stage solution procedure to minimize the total distance and cost in MRVRPTW. Liu and He [50] proposed a clustering-based multiple ant colony system algorithm to minimize the total cost for enhancing the route compactness in MRVRPTW. Ramos and Oliveira [51] developed a mathematical model to minimize the variable costs and attain equity, and designed a heuristic algorithm to address MRVRPTW. Liao [4] established the genetic mixed-integer nonlinear programming model to maximize total profit and designed a hybrid genetic algorithm to solve MRVRPTW. Govindan et al. [52] proposed a mathematical model and a fuzzy solution method to minimize the total cost in MRVRPTW.

TWA vehicle routing problem (TWAVRP) differs from the traditional VRPTW, where the service time windows are determined by customers. In TWAVRP, candidate time windows are assigned to customers to improve the operational efficiency of logistics networks [53, 54]. Subramanyam et al. [55] introduced a scenario decomposition algorithm to solve TWAVRP for minimizing the expected routing cost of logistics facility. Neves-Moreira et al. [56] presented a twostage stochastic optimization problem of TWAVRP and addressed it by using a fix-and-optimize-based metaheuristic. Jalilvand et al. [57] developed a stochastic model and a progressive hedging algorithm to minimize the routing cost. The results show that the efficiency of the proposed method has good performance in addressing TWAVRP. A mathematics model is proposed to enhance the operational efficiency and reduce the total cost, and a hybrid heuristic algorithm is used for TWAVRP [58].

The aforementioned literature covers many aspects of MRVRPRSTWA but has the following limitations: (1) The RS strategy is rarely considered between and within logistics facilities. (2) The TWA strategy is insufficiently discussed in multidepot logistics network optimization. (3) An efficient mathematical model for optimizing TNV in the presence of RS strategy is lacking. (4) The traditional evolutionary algorithms have limited applicability when solving the MRVRPRSTWA.

The contributions of this paper are as follows: (1) The RS strategy is incorporated in the MRVRPRSTWA to maximize resource utilization. (2) The TWA strategy is developed in the MRVRPRSTWA to improve the operational efficiency. (3) A bi-objective integer programming model is proposed to minimize the total operating cost and TNV in multidepot logistics networks with shared resources. (4) A hybrid heuristic algorithm, including 3D $k$-means clustering and NSGA-II, is developed to solve MRVRPRSTWA.

\section{Problem Statement}

The RS and TWA strategies are proposed in MRVRPRSTWA to optimize the recycling service of the multidepot logistics network. The multidepot logistics network is composed of multiple RCs and customers. Longdistance and crisscross trips often exist in the initial nonoptimal logistics network (Figure 1). The transportation resources are shared among logistics facilities, and customers with irrational time windows are reassigned new time windows to adjust optimized recycling routes through the TWA strategy. The comparison of the multidepot logistics network before and after optimization is shown in Figures 1 and 2.

In Figure 1, each RC operates independently in the nonoptimal logistics network. Several customers are served by the farther RC rather than the closer one. For example, customer 21 is closer to RC3, while it is served by RC1, resulting in long-distance and crisscross transportation. In addition, RCs can only provide on-time service for twothirds of customers, and the time windows for the remaining third of customers cannot be met. Relevant measures must be taken to enhance the operational efficiency and optimize the configuration of logistics networks. In Figure 2, centralized transportation is performed among RCs by a fleet of semitrailer trucks and is used to merge and transship goods between RCs, considering changes in customer demand assignment. Resources are shared among RCs, and customers are reassigned to the corresponding RC based on geographical locations and time windows. Irrational transportation phenomenon is reduced, and vehicles are shared among RCs. For example, due to the difference of service time between different routes, V2 is shared between $\mathrm{RC} 1$ and RC2, which first serve the customers of RC2 and then the customers of $\mathrm{RC} 1$, and thus the vehicle utilization rate is improved and the logistics operating cost is reduced. The violations of time windows are decreased when the TWA strategy is adopted. The RS and TWA strategies call for improving the utilization of transportation resources and operational efficiency and optimizing multidepot logistics networks.

This study assumes that the centralized transportation cost (TC) among logistics facilities is $\$ 22$ per unit time, and the recycling cost from logistics facilities to customers is $\$ 20$ per unit time. The penalty cost for earliness and delay service is $\$ 20$ per unit time. The assignment cost (AC) from the initial time window to assigned time (AT) window is $\$ 5$ per unit time. The maintenance cost (MC) of each semitrailer truck is $\$ 300$, and that of each vehicle is $\$ 200$. The AT, TNV, the number of semitrailer trucks (TNS), and the total cost are compared and listed in Table 1.

In Table 1, the total cost of reverse logistics network is decreased from $\$ 4640$ to $\$ 4170$. In addition, TNV is reduced from nine to five when sharing resources among logistics facilities. When the TWA strategy was applied, the penalty 


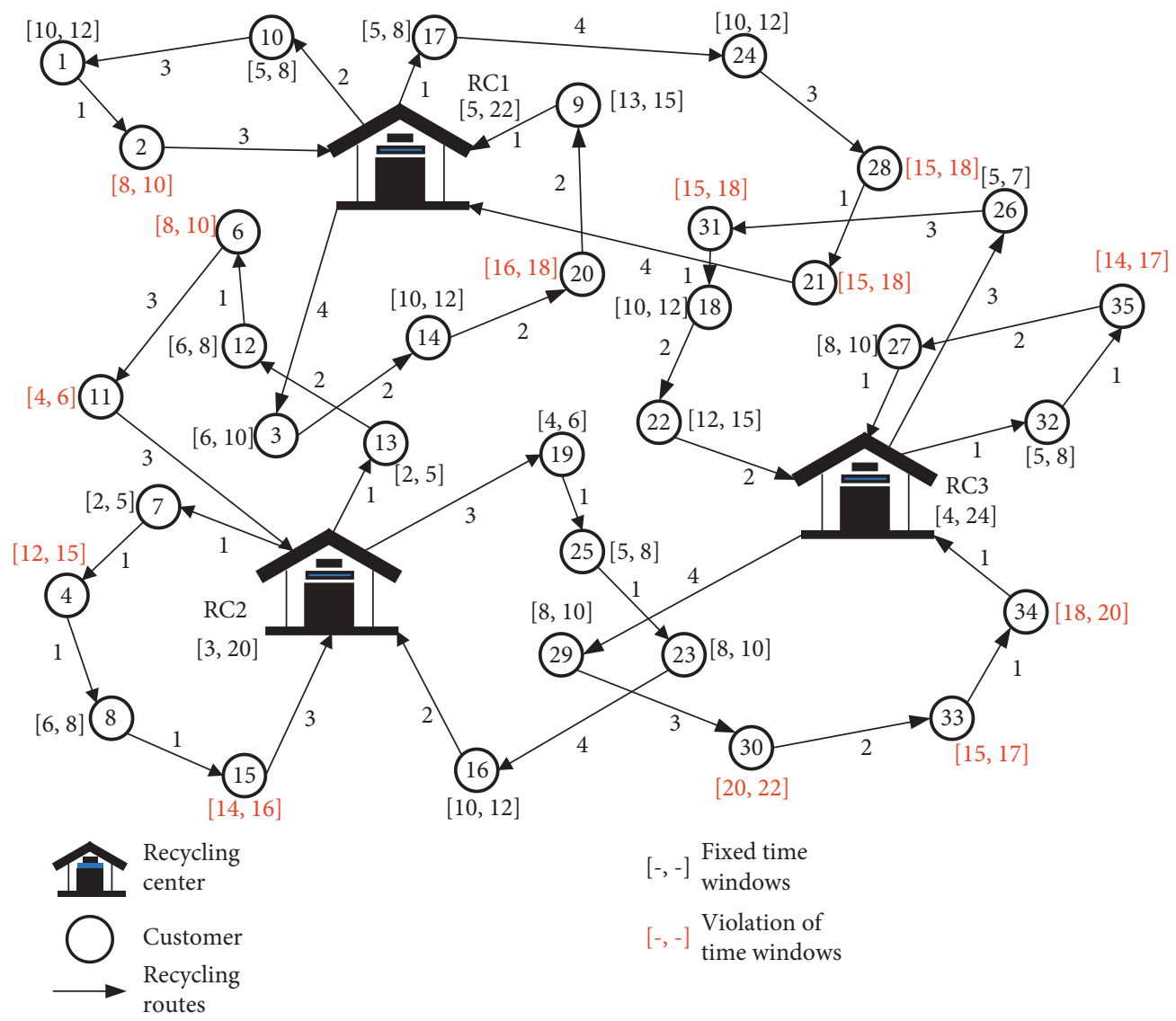

FIGURE 1: Logistics network without the RS and TWA strategies.

cost decreases by $63 \%$. The RS and TWA strategies can improve the resource utilization and operational efficiency and optimize multidepot logistics networks.

\section{Model Formulation for MRVRPTWA}

4.1. Related Definitions and Variables. In this section, the related notations and definitions on sets, parameters, and variables are shown in Table 2.

4.2. Mathematical Model. A bi-objective optimization model for MRVRPRSTWA is formulated to minimize the total operating cost in equation (1) and minimize TNV in equation (2).

$$
\begin{aligned}
\operatorname{Min} \mathrm{TC} & =\mathrm{TC}_{1}+\mathrm{TC}_{2}+\mathrm{TC}_{3}, \\
\operatorname{Min} \mathrm{MNV} & =\sum_{v \in V} \min \left\{\sum_{i \in P} \sum_{j \in C} x_{i j v}, 1\right\} .
\end{aligned}
$$

$\mathrm{TC}_{1}$ contains three components in equation (3): $\sum_{m \in P} \sum_{n \in P} \sum_{s \in S}\left(U_{s} \times D_{m n} \times W \times y_{m n s}\right)$ represents the centralized TCs by semitrailer trucks among logistics facilities. $\max \left\{\sum_{n \in P}\left(t q_{m n} / Q_{s}\right)\right\} \times\left(M_{s} / B\right)$ is the MC of semitrailer trucks. $\sum_{m \in P} \mathrm{FC}_{m}$ represents the fixed cost of logistics facilities.

$$
\begin{aligned}
\mathrm{TC}_{1}= & \sum_{m \in P} \sum_{n \in P} \sum_{s \in S}\left(U_{s} \times D_{m n} \times W \times y_{m n s}\right) \\
& +\max _{m \in P}\left\{\sum_{n \in P} \frac{t q_{m n}}{Q_{s}}\right\} \times \frac{M_{s}}{B}+\sum_{m \in P} \mathrm{FL}_{m} .
\end{aligned}
$$

$\mathrm{TC}_{2}$ contains two components in equation (4): $\sum_{i \in P \cup C} \sum_{j \in P \cup C} \sum_{v \in V}\left(U_{v} \times D_{i j} \times W \times x_{i j v}\right)$ is the TC by vehicles from logistics facilities to customers. $\sum_{v \in V} \min \left\{\sum_{i \in P} \sum_{j \in C} x_{i j v}, 1\right\} \times\left(M_{v} / B\right)$ represents the MC of vehicles.

$$
\begin{aligned}
\mathrm{TC}_{2}= & \sum_{i \in P \cup C} \sum_{j \in P \cup C} \sum_{v \in V}\left(U_{v} \times D_{i j} \times W \times x_{i j v}\right) \\
& +\sum_{v \in V} \min \left\{\sum_{i \in P} \sum_{j \in C} x_{i j v}, 1\right\} \times \frac{M_{v}}{B} .
\end{aligned}
$$

$\mathrm{TC}_{3}$ contains five components in equation (5): $\sum_{i \in P \cup C_{f}} \sum_{j \in C_{f}} \sum_{v \in V} \sum_{k \in O_{v}} x_{i j v} \times \mu_{e} \times\left[\max \left\{e_{i}-a t_{i v}^{k}, 0\right\}\right]$ and $\sum_{i \in P \cup C_{a}}$ $\sum_{j \in C_{a}} \sum_{v \in V} \sum_{k \in O_{v}} x_{i j v} \times \mu_{e} \times\left[\max \left\{\alpha_{i}-a t_{i v}^{k}, 0\right\}\right]$ represent the penalty cost caused by vehicles that provide earlier service than time windows of customers. $\sum_{i \in P \cup C_{a}} \sum_{j \in C_{a}}$ $\sum_{v \in V} \sum_{k \in O_{v}} x_{i j v} \times \mu_{d} \times\left[\max \left\{a t_{i v}^{k}-l_{i}, 0\right\}\right]$ and $\sum_{i \in P \cup C_{a}} \sum_{j \in C_{a}}$ $\sum_{v \in V} \sum_{k \in O_{v}} x_{i j v} \times \mu_{d} \times\left[\max \left\{a t_{i v}^{k}-\beta_{i}, 0\right\}\right]$ represent the 


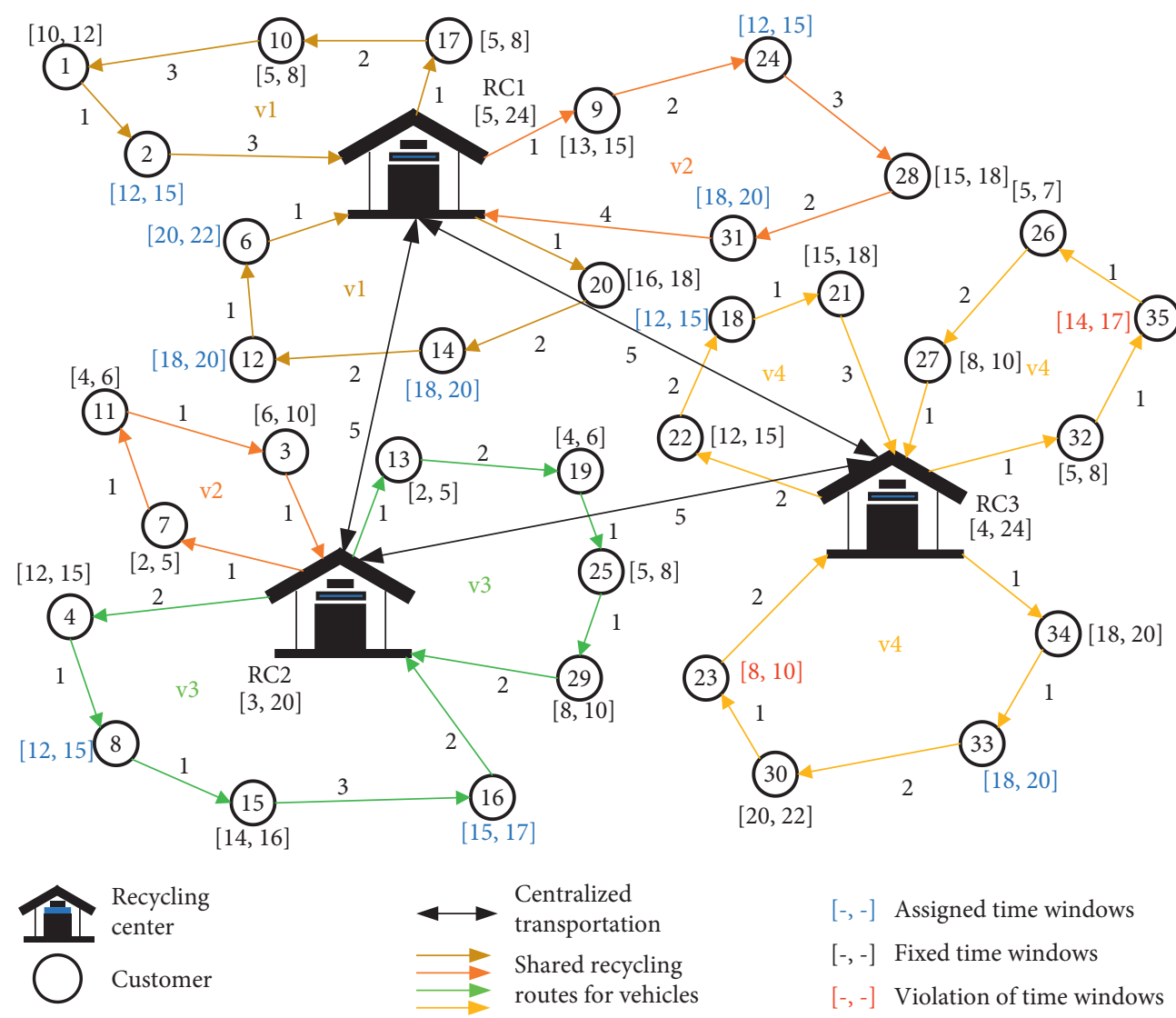

Figure 2: Logistics network with the RS and TWA strategies.

TABLE 1: Comparison of before and after RS and TWA.

Case TC (\$) Recycling cost (\$) Penalty cost (\$)

$\begin{array}{cccccc}\text { AT } & \text { AC (\$) } & \text { TNV } & \text { TNS } & \text { MC (\$) } & \text { Total cost (\$) } \\ - & - & 9 & - & 1800 & 4640 \\ 56 & 280 & 4 & 1 & 1100 & 4170\end{array}$

Nonoptimal logistics network
Optimal logistics with RS and TWA

-

1760
1400

$\begin{array}{lll}100 & - & - \\ 46 & 280\end{array}$

penalty cost caused by vehicles that provide delayed service than time windows of customers. $\sum_{i \in C_{a}} \mu_{a} \times$ $\left[\min \left\{\left|e_{i}^{\prime}-\alpha_{i}\right|,\left|\beta_{i}-l_{i}^{\prime}\right|\right\}\right]$ denotes the cost of TWA.

$$
\begin{aligned}
\mathrm{TC}_{3}= & \sum_{i \in P \cup C_{f}} \sum_{j \in C_{f}} \sum_{v \in V} \sum_{k \in O_{v}} x_{i j v} \times \mu_{e} \times\left[\max \left\{e_{i}-a t_{i v}^{k}, 0\right\}\right] \\
& +\sum_{i \in P \cup C_{f}} \sum_{j \in C_{f}} \sum_{v \in V} \sum_{k \in O_{v}} x_{i j v} \times \mu_{d} \times\left[\max \left\{a t_{i v}^{k}-l_{i}, 0\right\}\right] \\
& +\sum_{i \in P \cup C_{a}} \sum_{j \in C_{a}} \sum_{v \in V} \sum_{k \in O_{v}} x_{i j v} \times \mu_{e} \times\left[\max \left\{\alpha_{i}-a t_{i v}^{k}, 0\right\}\right] \\
& +\sum_{i \in P \cup C_{a}} \sum_{j \in C_{a}} \sum_{v \in V} \sum_{k \in O_{v}} x_{i j v} \times \mu_{d} \times\left[\max \left\{a t_{i v}^{k}-\beta_{i}, 0\right\}\right] \\
& +\sum_{i \in C_{a}} \mu_{a} \times\left[\min \left\{\left|e_{i}^{\prime}-\alpha_{i}\right|,\left|\beta_{i}-l_{i}^{\prime}\right|\right\}\right] .
\end{aligned}
$$


TABLE 2: Notations and definitions in the MRVRPRSTWA.

\begin{tabular}{|c|c|}
\hline \multicolumn{2}{|c|}{ Set definition } \\
\hline$P$ & Set of recycling centers (RCs), $P=\{p \mid p=1,2,3 \ldots, m\}$ and $m$ is the total number of RCs \\
\hline$C$ & Set of all recycling customers, $C=\{c \mid c=1,2,3 \ldots, h\}$ and $h$ is the total number of customers \\
\hline$C_{f}$ & Set of customers with fixed time windows \\
\hline$C_{a}$ & Set of customers with assigned time windows \\
\hline$V$ & Set of vehicles for recycling, $V=\{v \mid v=1,2,3 \ldots, b\}$ and $b$ is the total number of vehicles \\
\hline$S$ & Set of semitrailer trucks used between $\mathrm{RCs}, S=\{s \mid s=1,2,3 \ldots, w\}$ and $\mathrm{w}$ is the total number of vehicles \\
\hline$O_{v}$ & Maximum times for executing recycling routes of vehicle $v$ in a working period, $v \in V$ \\
\hline \multicolumn{2}{|r|}{ ( } \\
\hline$q_{i}$ & Recycling demand quantity of customer $i, i \in C$ \\
\hline$t q_{m n}$ & Transportation quantity from logistics facility $m$ to $n, m, n \in P$ \\
\hline$Q_{s}$ & Maximum capacity of semitrailer truck $s, s \in S$ \\
\hline$Q_{v}$ & Maximum capacity of vehicle $v, v \in V$ \\
\hline$Q_{m}$ & Maximum capacity of logistics facility $m, m \in P$ \\
\hline$U_{s}$ & Usage cost of semitrailer truck $s, s \in S$ (unit: dollar $/ \mathrm{km}$ ) \\
\hline$U_{v}$ & Usage cost of vehicle $v, v \in V$ (unit: dollar $/ \mathrm{km})$ \\
\hline$D_{i j}$ & Distance from logistics facility or customer $i$ to $j, i, j \in P \cup C, i \neq j$ (unit: $\mathrm{km}$ ) \\
\hline$D_{m n}$ & Distance from logistics facility $m$ to logistics facility $n, m, n \in P$ (unit: $\mathrm{km}$ ) \\
\hline$W$ & Number of working days in one planning period \\
\hline$B$ & Number of planning periods in one year \\
\hline$M_{s}$ & Annual MC of semitrailer truck $s, s \in S$ \\
\hline$M_{v}$ & Annual MC of vehicle $v, v \in V$ \\
\hline$F L_{m}$ & Fixed cost of logistics facility $m, m \in P$ \\
\hline$\left[e_{i}, t_{i}\right]$ & Fixed time window of customer $i, i \in C_{f}$ \\
\hline 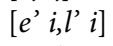 & Expected time window of customer $i, i \in C_{a}$ \\
\hline$\left[\alpha_{i}, \beta_{i}\right]$ & Time window assigned to customer $i, i \in C_{a}$ \\
\hline$\left[E_{m}, L_{m}\right]$ & Service time window of logistics facility $m, m \in P$ \\
\hline$\mu_{e}$ & Penalty cost for early arrival per unit time \\
\hline$\mu_{d}$ & Penalty cost for delayed arrival per unit time \\
\hline & Cost coefficient of the customer's time window from the expected time window to the assigned time window per unit time \\
\hline$d t k v m$ & Departure time of the $k$ th route of vehicle $\mathrm{V}$ from logistics facility $m, v \in V, m \in P, k \in O_{v}$ \\
\hline atk iv & Arrival time of the $k$ th route of vehicle $\mathrm{v}$ at node $i, v \in V, i \in P \cup C, k \in O_{v}$ \\
\hline & Travel time of vehicle $v$ between entities $i$ and $j, i, j \in P \cup C, v \in V$ \\
\hline$\left|N_{s}\right|$ & Total number of logistic facilities served by semitrailer truck $s, s \in \mathrm{S}$ \\
\hline$\left|N_{v}\right|$ & Total number of customers served by vehicle $v, v \in V$ \\
\hline$B N$ & \\
\hline \multicolumn{2}{|c|}{ Decision variables } \\
\hline $\begin{array}{l}x_{i j v} \\
z k v\end{array}$ & $\begin{array}{l}\text { If vehicle } v \text { travels from logistics facility or customer } i \text { to } j \text {, then } x_{i j v}=1 \text {; otherwise, } x_{i j v}=0, i, j \in P \cup C, v \in V \\
\text { If vehicle } v \text { has the } k \text { th route, then } z k v=1 \text {; otherwise, } z k v=0, m \in P, v \in V \text {, and } k \in O_{v}\end{array}$ \\
\hline$\omega_{i v m}$ & If vehicle $v$ departs from logistics facility $m$ to served customer $i, \omega_{i v m}=1$; otherwise, $\omega_{i v m}=0, i \in C, v \in V$, and $m \in P$ \\
\hline$y_{m n s}$ & If semitrailer truck $s$ transports between logistics facility $m$ and $n, y_{m n k}=1$; otherwise, $y_{m n s}=0, m, n \in P$, and $s \in S$ \\
\hline$\tau_{i m n}$ & $\begin{array}{l}\text { If customer } i \text { 's logistic facility changes from logistics facility } m \text { to } n \text { after optimization, } \boldsymbol{\tau}_{i m n}=1 \text {; otherwise, } \boldsymbol{\tau}_{i m n}=0, i \in C \text {, and } \\
\text { m, } n \in P\end{array}$ \\
\hline$g_{m s}$ & If semitrailer truck $s$ departs from logistics facility $m, g_{m s}=1$; otherwise, $g_{m s}=0, s \in S$, and $m \in P$ \\
\hline
\end{tabular}


Subject to

$$
\begin{aligned}
& \sum_{m \in P} y_{m n s}=1, \quad \forall n \in P, s \in S, m \neq n, \\
& \sum_{n \in P} y_{m n s}-\sum_{n \in P} y_{n f s}=0, \quad \forall m, f \in P, m \neq f, s \in S, \\
& \sum_{m \in P} y_{n m s}=1, \quad \forall n \in P, s \in S, m \neq n, \\
& \sum_{m \in P} \sum_{n \in P} y_{m n s} \times g_{p s} \leq\left|N_{s}\right|-1, \quad \forall p \in P, s \in S, p \neq m, p \neq n, \\
& t q_{m n}=\sum_{i \in C} \tau_{i m n} \times q_{i}, \quad \forall m, n \in P, \\
& \sum_{m \in P} \sum_{n \in P} t q_{m n} \times y_{m n s} \leq Q_{s}, \quad \forall s \in S, \\
& \sum_{i \in P} x_{i j v}=1, \quad \forall j \in C, v \in V, \\
& \sum_{i \in C} \sum_{j \in C} x_{i j v}=1, \quad \forall v \in V \\
& \sum_{j \in P} x_{i j v}-\sum_{j \in P} x_{j f v}=0, \quad \forall i, f \in P \cup C, i \neq f, v \in V, \\
& \sum_{i \in P} x_{j i v}=1, \quad \forall j \in C, v \in V, \\
& \sum_{i \in C} \sum_{j \in C} x_{i j v} \leq\left|N_{v}\right|-1, \quad \forall v \in V, \\
& \sum_{j \in C} q_{j} \times x_{i j v} \times z_{v}^{k} \leq Q_{v}, \quad \forall i \in P \cup C, v \in V, k \in O_{v}, \\
& \sum_{j \in C} \sum_{v \in V} q_{j} \times \omega_{i j v m} \leq Q_{m}, \quad \forall i \in P \cup C, m \in P, \\
& d t_{v m}^{k}+t_{m i v}-B N\left(1-x_{m i v}\right) \leq a t_{i v}^{k}, \quad \forall m \in P, i \in C, v \in V, k \in O_{v}, \\
& d t_{v m}^{k}+t_{m i v}+B N\left(1-x_{m i v}\right) \geq a t_{i v}^{k}, \quad \forall m \in P, i \in C, v \in V, k \in O_{v}, \\
& a t_{i v}^{k}+t_{i j v}-B N\left(1-x_{i j v}\right) \leq a t_{j v}^{k}, \quad \forall i \in C, j \in C \cup P, v \in V, k \in O_{v}, \\
& a t_{i v}^{k}+t_{i j v}+B N\left(1-x_{i j v}\right) \geq a t_{j v}^{k}, \quad \forall i \in C, j \in C \cup P, v \in V, k \in O_{v}, \\
& E_{m} \times x_{\text {miv }} \times z_{v}^{k} \leq d t_{v m}^{k} \leq L_{m} \times x_{\text {miv }} \times z_{v}^{k}, \quad \forall m \in P, i \in C, v \in V, k \in O_{v}, \\
& E_{m} \times x_{m i v} \times z_{v}^{k} \leq a t_{m v}^{k} \leq L_{m} \times x_{m i v} \times z_{v}^{k}, \quad \forall m \in P, i \in C, v \in V, k \in O_{v}, \\
& a t_{m v}^{k}+t_{m n v}-M\left(1-z_{v}^{k+1}\right) \leq d t_{v n}^{k+1}, \quad \forall m, n \in P, v \in V, k \in O_{v},
\end{aligned}
$$




$$
\begin{aligned}
& x_{i j v}=\{0,1\}, \quad \forall i, j \in P \cup C, v \in V, \\
& z_{v}^{k}=\{0,1\}, \quad \forall v \in V, k \in O_{v}, \\
& \omega_{i v m}=\{0,1\}, \quad \forall i \in C, v \in V, m \in P, \\
& y_{m n s}=\{0,1\}, \quad \forall m, n \in P, \forall s \in S, \\
& \tau_{i m n}=\{0,1\}, \quad \forall i \in C, \forall m, n \in P, m \neq n, \\
& g_{m s}=\{0,1\}, \quad \forall m \in P, s \in S .
\end{aligned}
$$

Constraint (6) ensures that each semitrailer truck originally departs from logistics facilities. Constraint (7) is the flow conservation on each logistics facility. Constraint (8) ensures that each semitrailer truck finally returns to logistics facilities. Constraint (9) is used to avoid subtours for semitrailer trucks. Constraint (10) calculates the transportation quantity among logistics facilities. Constraint (11) stipulates that each semitrailer truck has enough capacity to satisfy the transportation quantity of the assigned logistics facilities. Constraint (12) ensures that each vehicle departs from logistics facilities only. Constraint (13) ensures that each customer can be served once by one vehicle. Constraint (14) is the flow conservation on each customer. Constraint (15) ensures that each vehicle finally returns to logistics facilities. Constraint (16) is used to avoid subtours for vehicles. Constraint (17) represents that each vehicle has enough capacity to satisfy the total demand of assigned customers. Constraint (18) ensures that the total demand of customers served by a logistics facility should be beyond its capacity. Constraints (19) and (20) guarantee the continuous departure time of vehicles at logistics facilities. Constraints (21) and (22) guarantee the continuous arrival time of vehicles at customers. Constraints (23) and (24) guarantee the departure and return times of vehicles at logistics facilities. Constraint (25) ensures the continuous departure time of shared routes of each vehicle. Constraints (26)-(31) indicate the binary restrictions on decision variables.

\section{Solution Procedure}

The hybrid heuristic algorithm is widely applied to solve multiobjective optimization problems [59-61]. This algorithm, including the $3 \mathrm{D} k$-means clustering and NSGA-II algorithms, is proposed to solve the MRVRPRSTWA. The 3D $k$-means clustering algorithm is often utilized to construct clusters according to the spatial and temporal distances of data [53]. The 3D $k$-means clustering algorithm can effectively reduce the computational complexity of multidepot logistics networks [37]. The NSGA-II can assign appropriate time windows to customers and obtain Pareto optimal solutions in MRVRPRSTWA. The elitist strategy in NSGA-II can effectively avoid the loss of the best individual and enhance the computational speed and robustness. The elitist strategy is composed of the genetic operations (i.e., selection, crossover, and mutation) and the fast nondominated sorting and crowding distance. The parameters utilized in the flow structure are defined as follows: $i$ is the number of RCs and clustering centers, $R$ is set as the present number of optimization runs, Rmax represents the maximum number of optimization runs, $N$ is set as the present number of generations, and Nmax is set as the maximum number of generations. The flow structure of the hybrid heuristic algorithm is shown in Figure 3.

The optimization procedure of MRVRPRSTWA is as follows:

Step 1: 3D $k$-means clustering. Set the number of RCs as the number of clusters and the data from RCs as the initial data of each cluster. Calculate the spatial and temporal distances between cluster centers and customers. Assign each customer to the nearest cluster center.

Step 2: the NSGA-II algorithm is used to establish pickup vehicle routes. The initial parameters are set and the initial population is randomly generated.

Step 3: genetic operation, including selection, partialmapped crossover (PMC), and mutation is performed to generate offspring population. The parent and offspring population are combined.

Step 4: the new population is selected by performing nondominated sorting and calculating the crowding distance of each individual.

Step 5: determine whether the internal termination is satisfied. If the termination condition is unsatisfied, then select customers that accepted the TWA strategy and have time window violations, and assign the appropriate time windows to them; otherwise, return to Step 3.

Step 6: calculate the total cost and TNV with the adoption of the TWA strategy by NSGA-II and determine whether the termination condition is satisfied. If the termination condition is unsatisfied, then return to Step 1 to confirm whether the clustering results need to be adjusted; otherwise, terminate the algorithm procedure and find the optimal solution. 


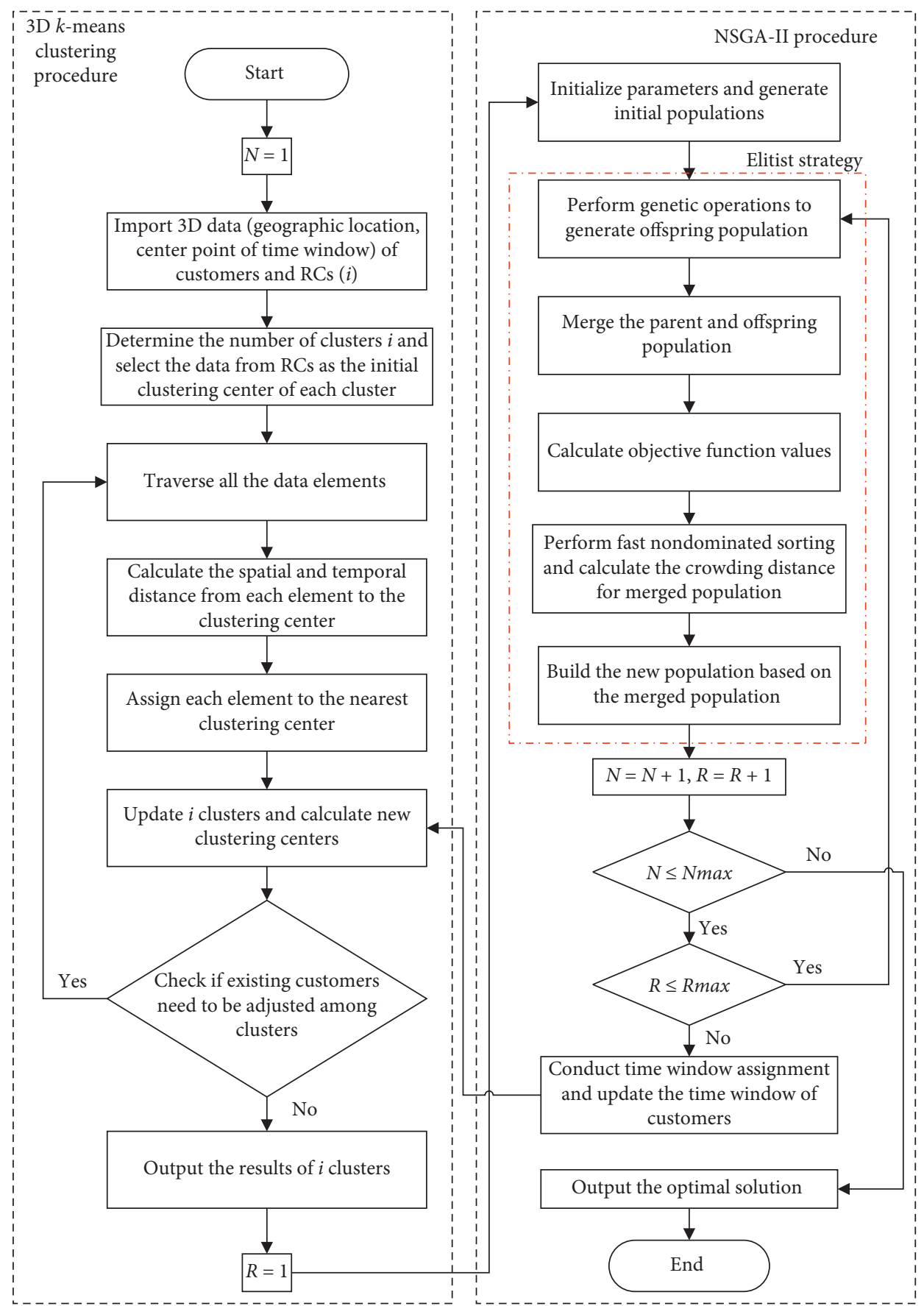

FIGURE 3: Algorithm flow structure for MRVRPRSTWA.

5.1. 3D k-Means Clustering. The clustering algorithm is always utilized to construct clusters to each depot in multidepot VRP to reduce computational complexity $[62,63]$. The traditional $k$-means clustering algorithm groups customers on the basis of the spatial distances between customers and clustering centers $[64,65]$. The $3 \mathrm{D} k$-means clustering algorithm, a variant of the traditional $k$-means clustering algorithm, constructs clusters according to the spatial and temporal distances among clustering centers and customers. In this study, the 3D $k$-means clustering algorithm is applied to optimize MRVRPRSTWA. The spatial and temporal distances based on geographic coordinates and time windows of customers and logistics facilities can be calculated by

$$
\beta_{1}+\beta_{2}=1
$$

$$
\operatorname{dis}=\beta_{1}\left(\left|x_{m}-x_{p}\right|+\left|y_{m}-y_{p}\right|\right)+\beta_{2}\left|z_{m}-z_{p}\right| \text {. }
$$

In equation (32), $\beta_{1}$ and $\beta_{2}$ represent the proportion of spatial and temporal distances, respectively. In equation (33), $\left(x_{m}, y_{m}, z_{m}\right)$ expresses the geographic location and center point of time windows of logistics facility. $\left(x_{p}, y_{p}, z_{p}\right)$ 
expresses the geographic location and center point of time windows of customer. The 3D $k$-means clustering algorithm procedure is shown in Algorithm 1.

In Algorithm 1, the process of clustering can be divided into several components: First, the geographic locations and center point of the time windows of RCs and customers are used to construct the initial 3D data elements. Second, set $i$ on the basis of the number of RCs as the number of clusters and the data from RCs as the initial clustering center of each cluster. Third, traverse data elements and calculate the spatial and temporal distances from each element to every clustering center. Fourth, assign each element to the nearest clustering center, and elements assigned to the same clustering center are placed in one cluster. Fifth, update $i$ clusters, and continue to execute this procedure till no existing customers need to be adjusted among clusters; then, $i$ clusters, including RCs and their served customers, are reported. The clustering results provide the initial population for multidepot vehicle routing optimization.

5.2. NSGA-II. Heuristic algorithms have obvious performances in solving multidepot logistics networks [66]. The NSGA-II is an enhanced algorithm based on the NSGA to solve multiobjective evolutionary problems $[67,68]$. NSGAII ranks different individuals via nondominated sorting algorithm and crowding distance comparison operators to force individuals to converge toward and diffuse along the Pareto front. The main procedures of NSGA-II are summarized below.

5.2.1. Selection. The selection operation involves choosing certain individuals every time from the parent population with selection probability $s p$, and the best individual will be inserted into the offspring population. The selection operation will continue until the offspring population size reaches a predetermined size. The specific steps can be described as follows: First, individuals are chosen from the parent population with selection probability $s p$ at random. Then, the individual with the best fitness values is selected and added into the offspring population. The abovementioned procedures are repeated until the offspring population reaches a predetermined size.

5.2.2. $P M C$. $P M C$ is used as the operator of the crossover operation [69]. The specific procedure of PMC is shown in Figure 4, and the main steps of PMC are as follows: First, randomly select the beginning and ending positions of a gene sequence of a pair of chromosomes. Second, the two sets of genes selected on the two chromosomes are exchanged separately. Third, conduct conflict detection and establish a mapping relationship on the exchanged genes. Fourth, repeat this step until no duplicate genes are present on the same chromosome.

The mapping relationship is illustrated in Figure 4. For example, a mapping relationship of 3-1and 5-6 genes is presented. Two genes 3 in offspring1 are selected in the second step, and the unselected gene is transformed into 1 .
Two genes 5 in offspring 1 are selected in the third step, and the unselected gene is transformed into 6. Finally, two children with no conflict genes are generated.

5.2.3. Mutation. Mutation operation aims to change the values of a gene at a certain locus of chromosome to generate a new chromosome [70]. Polynomial mutation is used in this work to prevent local convergence in the course of evolution. The main steps of polynomial mutation are shown in Figure 5.

In Figure 5, a chromosome is randomly selected from the parent generation in terms of the mutation probability $p c$. Then, three genes on the parental chromosome are randomly selected, and the exchange and regenerated operation are conducted on the three genes. If duplicate genes appear, then they should be removed and regenerated.

5.2.4. Nondominated Sorting and Crowding Distance Assignment. Several definitions are provided to describe the procedures of nondominated sorting and crowding distance. $N$ represents the set of population, and it can be divided into several subsets (i.e., $A_{1}, A_{2}, A_{3}$..). The subsets can be indicated as follows: $A_{1}$ is the set of nondominated population of $N, A_{2}$ is the set of nondominated population of $N-A_{1}, A_{3}$ is the set of nondominated population of $N-\left(A_{1} \cup A_{2}\right)$, and so on. In each individual $m$, let $i d(m)$ be the index of the front to which $m$ belongs and $c d(m)$ be the crowding distance of $m$. The crowding distance can be calculated in equation (34) as follows:

$$
c d(m)=\frac{f_{1}\left(m_{1}\right)-f_{1}\left(m_{2}\right)}{f_{1}^{\max }-f_{1}^{\min }}+\frac{f_{2}\left(m_{3}\right)-f_{2}\left(m_{4}\right)}{f_{2}^{\max }-f_{2}^{\min }},
$$

where $m_{1}$ and $m_{2}$ are the closest populations of $m$ in the same front on the basis of $f_{1} ; m_{3}$ and $m_{4}$ are the closest populations of $m$ in the same front on the basis of $f_{2}$; and fmax and fmin are the maximum and minimum values of $f_{i}$, respectively. In addition, if $n$ is the boundary individual, then the crowding distance of $n$ is infinity, namely, $c d(n)=\infty$. If the $i d(m)$ is smaller than the $i d\left(m^{\prime}\right)$ or $i d(m)$ is equal to the $i d(m)$, and the $c d(m)$ is larger than the $c d(m)$, then we can say $m$ is preferred to $m$ ". The next generation is selected through the abovementioned method, which is nondominated sorting and crowding distance [71].

5.2.5. TWA Strategy. The TWA strategy is designed in the NSGA-II algorithm to assign candidate time windows to customers with improved operational efficiency. The main procedures are presented as follows:

Step 1: customers that accepted the TWA strategy with violation of time windows are selected.

Step 2: assume that the time window for customer $A$ is $\left[E_{A}, L_{A}\right]$, and the actual service time of customer $\mathrm{A}$ is $i$ hours earlier (or delayed) than $E_{A}$. If $E_{A}-i$ (or $L_{A}+i$ ) is between the candidate time window $\left[E^{\prime} A, L^{\prime} A\right]$, then calculate the TWA cost, and compare it with the penalty cost. 
Input: Number of RCs, geographic coordinates, and time windows of customers and RCs

Output: Clusters, including RCs and their assigned customers

(1) Import the geographic locations and center point of the time windows of RCs and customers as initial data.

(2) Establish $3 \mathrm{D}$ vectors on the basis of the initial data and construct $3 \mathrm{D}$ data elements.

(3) Set $i$ as the number of clusters on the basis of the number of RCs.

(4) Select the data from RCs as the initial clustering center of each cluster.

(5) Traverse all the data elements.

(6) Calculate the spatial and temporal distances from each element to the clustering center.

(7) Assign each element to the nearest clustering center.

(8) Update $i$ clusters, and calculate new clustering centers.

(9) If existing customers need to be adjusted among clusters

(10) Then return to step 5;

(11) Else

(12) End if

(13) End for

(14) Output the results of $i$ clusters.

Algorithm 1: 3D $k$-means clustering algorithm.

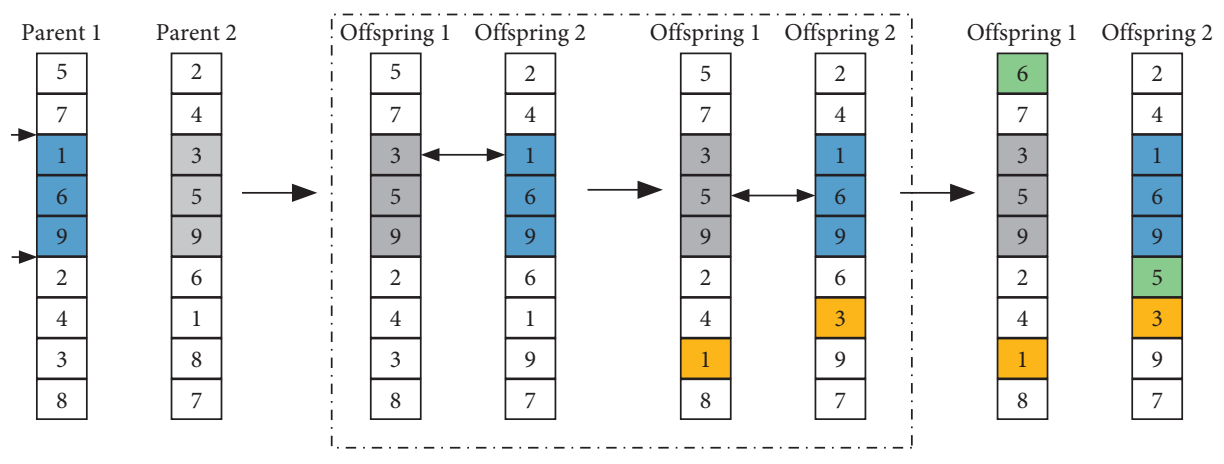

FIgUre 4: Procedure of PMC.

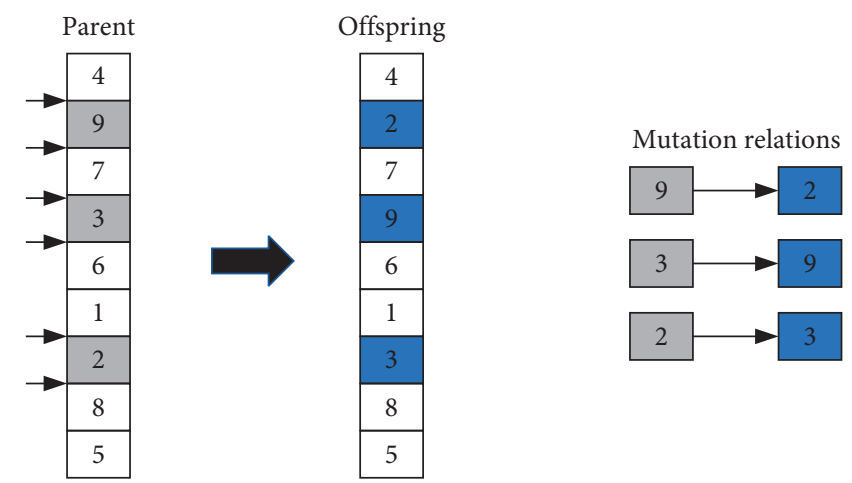

Figure 5: Procedure of mutation.

Step 3: if the TWA cost is lower than the penalty cost, then $\left[E^{\prime} A, L^{\prime} A\right]$ will assign to customer $A$; otherwise, keep the initial time window of customer $A$.

Therefore, the appropriate time windows are assigned to the corresponding customers. The process of NSGA-II is described in Algorithm 2.

\section{Implementation and Analysis}

6.1. Algorithm Comparison. In this section, benchmark instances are performed to test the quality of NSGA-II in MRVRPRSTWA for comparing its results with those received by multiobjective evolutionary algorithm (MOEA) [72] and multiobjective particle swarm optimization 
Nondominated Sorting Algorithm-II (NSGA-II)

Input: pop ${ }_{\text {size }}$, nodes, $R, R \max , N \max , s p, c p$, and $m p$

Output: Pareto front optimal solutions

(1) Initialize parameters

(2) \# set the population size ( pop $_{\text {size }}$ ), number of customers (nodes), number of generation $(R)$, maximum number of generations $(R \max )$, maximum number of runs $(N \max )$, selection probability $(s p)$, crossover probability $(c p)$, and mutation probability $(m p)$

(3) For $N=1: N \max$

(4) For $R=1: R \max$

(5) Generate the initial population with size pop size

(6) Objective function evaluation

(7) \# compute the objective function to minimize the total operating cost and TNV

(8) Divide pop $_{\text {size }}$ into nondominance front and calculate the crowding distance of each individual

(9) For $i=1: R$

(10) Implement selection, PMC, and mutation operations to generate offspring population

(11) Combine parent and offspring population, perform nondominated sorting and calculate the crowding distance of each individual

(12) Build the new population on the basis of the parent and offspring populations following partial order

(13) end

(14) end

(15) For $n=1$ : nodes

(16) Select the customers that accept time window and have time window violation

(17) Select the appropriate time window from candidate time windows to assign to customer

(18) Calculate the TWA cost and compare it with the penalty cost

(19) Assign the time window to the customer or keep the expected time window of customer

(20) end

(21) Find the Pareto front optimal solution

(22) end

Algorithm 2: NSGA-II algorithm operation.

(MOPSO) [73]. The multidepot VRPTW (MDVRPTW) datasets obtained from the database of the NEO research group (https://neo.lcc.uma.es/vrp/vrp-instances/multipledepot-vrp-with-time-windows-instances/) are illustrated in Table 3.

Table 3 presents the relevant characteristics of 20 benchmarks. The parameters for NSGA-II and MOEA are as follows: population size pop $_{\text {size }}=150$, selection probability $s p=0.6$, crossover probability $c p=0.9$, and mutation probability $m p=0.1$. The parameters for MOPSO are as follows: maximum iteration number max_it $=200$, inertia weight $\omega=0.9$, personal confidences $p c=2$, and social learning confidences $g c=3$. The results of the three algorithms, which contain total cost (cost), TNV (vehicle), and computation time (Ct), are compared in Table 4.

Table 4 exhibits an adequate difference among the optimal results of those three algorithms on the basis of the values of $t$-test and $p$-value. The NSGA-II algorithm is superior to MOEA and MOPSO in obtaining the optimal cost in MRVRPRSTWA. The costs of MOEA and MOPSO are higher than that of NSGA-II in 20 benchmark instances. For instance, the average cost of NSGA-II is $\$ 15479$. However, the costs of MOEA and MOPSO are \$20019 and $\$ 17520$, respectively. The minimum number of vehicles calculated by NSGA-II is nine compared to TNV of MOEA and MOPSO. The NSGA-II outperforms MOEA and MOPSO in terms of the minimum computation time. The average computation time of NSGA-II is 237s, which is lower than the computation times of MOEA and MOPSO.
Therefore, the NSGA-II algorithm can achieve better performance in solving MRVRPRSTWA compared to MOEA and MOPSO.

6.2. Data Source. A real reverse logistics network in Chongqing, China, is used to verify the applicability and feasibility of the proposed solution in MRVRPRSTWA. The logistics network has five RCs (i.e., RC1, RC2, RC3, RC4, and RC5) and 183 customers. The spatial distribution of logistics network is shown in Figure 6. The RCs and customers are marked as stars and rhombuses, respectively. Rhombuses in various colors represent customers served by different RCs. The initial vehicle routes are shown in Table 5 .

In Table 5, customers are served by 21 vehicle routes among five RCs. Each RC is operated independently, which results in the waste of resources. For example, three customers (i.e., P180, P177, and P171) belonging to RC1 and two customers (i.e., P75 and P65) belonging to RC5 are served by a vehicle, respectively. The irrational vehicle routes should be decreased to enhance the operational efficiency of the multidepot logistics network.

6.3. Relevant Parameter Setting. The objective of MRVRPRSTWA is to obtain the lowest operating cost and TNV in the multidepot reverse logistics network. The related parameters used in the optimization model and the hybrid heuristic algorithm initialization are shown in Table 6. The time window of RC1 is $[6,18]$. RC2 and RC3 have the same 
TABLE 3: Relevant settings of data instances.

\begin{tabular}{|c|c|c|c|c|c|}
\hline Instances & Datasets & Number of depots & Number of customers & Number of candidate time windows & Vehicle capacity \\
\hline 1 & MDPR1 & 4 & 48 & 2 & 200 \\
\hline 2 & MDPR2 & 4 & 96 & 2 & 195 \\
\hline 3 & MDPR3 & 4 & 144 & 3 & 190 \\
\hline 4 & MDPR4 & 4 & 192 & 4 & 185 \\
\hline 5 & MDPR5 & 4 & 240 & 4 & 180 \\
\hline 6 & MDPR6 & 4 & 288 & 5 & 175 \\
\hline 7 & MDPR7 & 6 & 72 & 2 & 200 \\
\hline 8 & MDPR8 & 6 & 144 & 3 & 190 \\
\hline 9 & MDPR9 & 6 & 216 & 4 & 180 \\
\hline 10 & MDPR10 & 6 & 288 & 5 & 170 \\
\hline 11 & MDPR11 & 4 & 48 & 2 & 200 \\
\hline 12 & MDPR12 & 4 & 96 & 2 & 195 \\
\hline 13 & MDPR13 & 4 & 144 & 3 & 190 \\
\hline 14 & MDPR14 & 4 & 192 & 4 & 185 \\
\hline 15 & MDPR15 & 4 & 240 & 4 & 180 \\
\hline 16 & MDPR16 & 4 & 288 & 5 & 175 \\
\hline 17 & MDPR17 & 6 & 72 & 2 & 200 \\
\hline 18 & MDPR18 & 6 & 144 & 3 & 190 \\
\hline 19 & MDPR19 & 6 & 216 & 4 & 180 \\
\hline 20 & MDPR20 & 6 & 288 & 5 & 170 \\
\hline
\end{tabular}

TABLE 4: Comparison of the results of the three algorithms on different instances.

\begin{tabular}{|c|c|c|c|c|c|c|c|c|c|}
\hline \multirow{2}{*}{ Instances } & \multicolumn{3}{|c|}{ NSGA-II } & \multicolumn{3}{|c|}{ MOEA } & \multicolumn{3}{|c|}{ MOPSO } \\
\hline & Cost (\$) & Vehicle & $\mathrm{Ct}(\mathrm{s})$ & Cost $(\$)$ & Vehicle & $\mathrm{Ct}(\mathrm{s})$ & Cost $(\$)$ & Vehicle & $\mathrm{Ct}(\mathrm{s})$ \\
\hline 1 & 8450 & 3 & 184 & 12742 & 7 & 189 & 10689 & 5 & 179 \\
\hline 2 & 9617 & 4 & 195 & 14906 & 9 & 221 & 12837 & 7 & 204 \\
\hline 3 & 13716 & 8 & 210 & 16137 & 10 & 211 & 15067 & 9 & 215 \\
\hline 4 & 15764 & 10 & 225 & 18940 & 13 & 243 & 19923 & 14 & 231 \\
\hline 5 & 15829 & 10 & 231 & 21070 & 15 & 238 & 18041 & 12 & 244 \\
\hline 6 & 17032 & 11 & 251 & 21412 & 15 & 267 & 19338 & 13 & 247 \\
\hline 7 & 16952 & 9 & 250 & 20373 & 12 & 255 & 17325 & 9 & 261 \\
\hline 8 & 20048 & 12 & 254 & 23601 & 15 & 248 & 18550 & 10 & 269 \\
\hline 9 & 17968 & 10 & 266 & 25526 & 17 & 261 & 22484 & 14 & 268 \\
\hline 10 & 19119 & 11 & 278 & 23500 & 15 & 287 & 19454 & 11 & 288 \\
\hline 11 & 8335 & 3 & 207 & 14720 & 9 & 210 & 8673 & 3 & 217 \\
\hline 12 & 10598 & 5 & 216 & 15840 & 10 & 231 & 14772 & 9 & 231 \\
\hline 13 & 12743 & 7 & 224 & 19165 & 13 & 242 & 17094 & 11 & 233 \\
\hline 14 & 15789 & 10 & 230 & 20110 & 14 & 257 & 18053 & 12 & 246 \\
\hline 15 & 15929 & 10 & 237 & 21171 & 15 & 241 & 17119 & 11 & 251 \\
\hline 16 & 18074 & 12 & 241 & 20260 & 14 & 246 & 19231 & 13 & 265 \\
\hline 17 & 15932 & 8 & 251 & 21234 & 13 & 279 & 20173 & 12 & 271 \\
\hline 18 & 18158 & 10 & 257 & 19411 & 11 & 264 & 19367 & 11 & 279 \\
\hline 19 & 19998 & 12 & 262 & 24482 & 16 & 298 & 21461 & 13 & 278 \\
\hline 20 & 19537 & 11 & 268 & 25779 & 17 & 317 & 20742 & 12 & 288 \\
\hline Average & 15479 & 9 & 237 & 20019 & 13 & 250 & 17520 & 11 & 248 \\
\hline$t$-test & & & & -12.955 & & & -5.529 & & \\
\hline$p$-value & & & & $3.51502 \mathrm{E}-11$ & & & $1.24 \mathrm{E}-05$ & & \\
\hline
\end{tabular}

time window $[8,20]$. The time window of RC4 and RC5 is the same as $[10,22]$. The candidate time windows are constructed on the basis of the real situation of customers that accepted TWA. Hence, four candidate time windows are constructed: $[8,10],[10,11],[12,15]$, and $[16,18]$.

6.4. Optimization Results. Customers are clustered on the basis of the $3 \mathrm{D} k$-means clustering algorithm to reduce the computational complexity in the multidepot reverse logistics network. Customers are reassigned to the $\mathrm{RC}$ with the nearest spatial and temporal distances. The results of the 3D $k$-means clustering algorithm are shown in Table 7 and Figure 7.

Table 7 illustrates that 183 customers are reassigned to the corresponding logistics facilities and grouped into five clusters. RC1 is allocated 28 customers, RC2 is allocated 28 customers, RC3 is allocated 42 customers, and RC4 and RC5 are allocated 42 and 43 customers, respectively. The spatial and temporal distances of the customers are shown in 


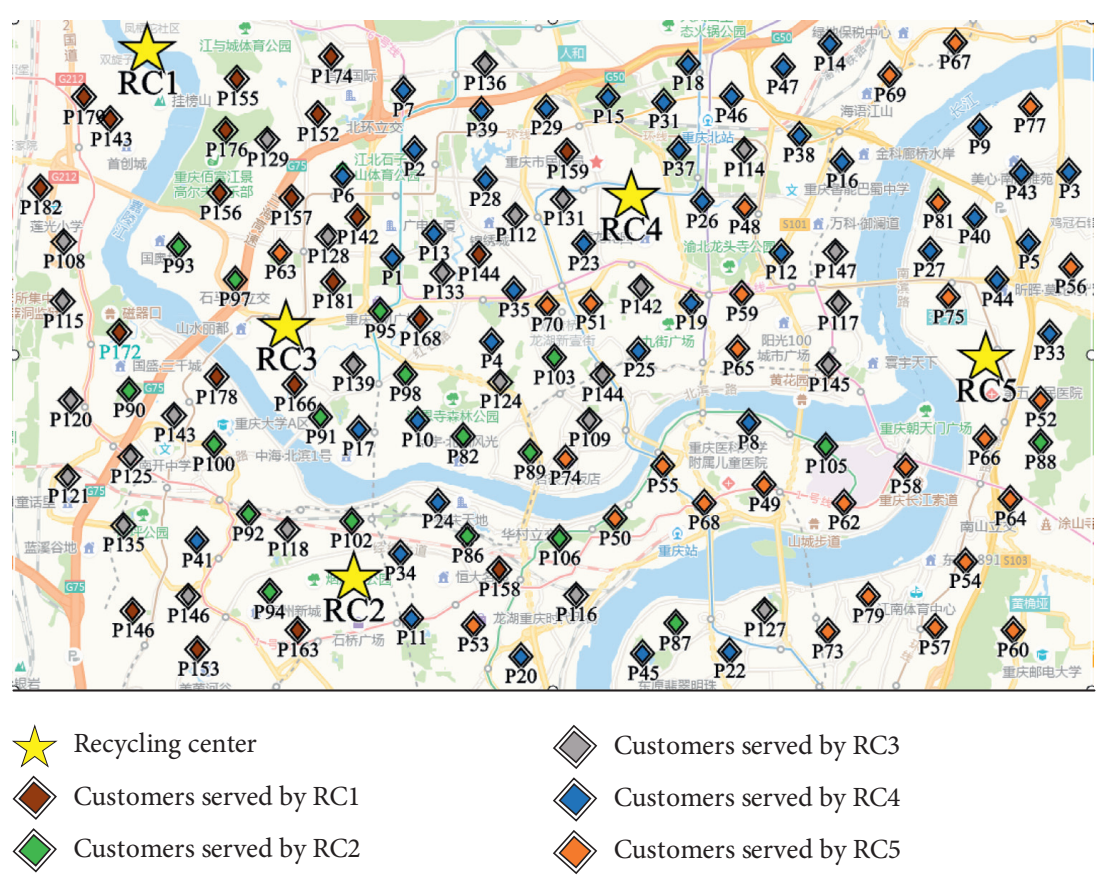

FIgURE 6: Spatial distribution of RCs and customers.

TABLE 5: Initial vehicle routes before optimization.

\begin{tabular}{|c|c|}
\hline Facilities & Routes \\
\hline RC1 & $\begin{array}{l}\mathrm{RC} 1 \longrightarrow \mathrm{P} 175 \longrightarrow \mathrm{P} 174 \longrightarrow \mathrm{P} 167 \longrightarrow \mathrm{P} 157 \longrightarrow \mathrm{P} 163 \longrightarrow \mathrm{P} 172 \longrightarrow \mathrm{P} 169 \longrightarrow \mathrm{P} 176 \longrightarrow \mathrm{P} 162 \longrightarrow \mathrm{P} 179 \longrightarrow \mathrm{P} 155 \longrightarrow \mathrm{RC} 1 \\
\mathrm{RC} 1 \longrightarrow \mathrm{P} 150 \longrightarrow \mathrm{P} 159 \longrightarrow \mathrm{P} 152 \longrightarrow \mathrm{P} 165 \longrightarrow \mathrm{P} 180 \longrightarrow \mathrm{P} 177 \rightarrow \mathrm{P} 171 \longrightarrow \mathrm{RC} 1 \\
\mathrm{RC} 1 \longrightarrow \mathrm{P} 182 \longrightarrow \mathrm{P} 161 \longrightarrow \mathrm{P} 170 \longrightarrow \mathrm{P} 154 \longrightarrow \mathrm{P} 181 \longrightarrow \mathrm{P} 158 \longrightarrow \mathrm{RC} 1 \\
\longrightarrow \mathrm{P} 156 \longrightarrow \mathrm{P} 183 \longrightarrow \mathrm{P} 160 \longrightarrow \mathrm{P} 153 \longrightarrow \mathrm{P} 166 \longrightarrow \mathrm{P} 151 \longrightarrow \mathrm{P} 178 \longrightarrow \mathrm{P} 173 \longrightarrow \mathrm{RC} 1\end{array}$ \\
\hline RC2 & $\begin{array}{c}\mathrm{RC2} \longrightarrow \mathrm{P} 98 \longrightarrow \mathrm{P} 107 \longrightarrow \mathrm{P} 95 \longrightarrow \mathrm{P} 97 \longrightarrow \mathrm{P} 99 \longrightarrow \mathrm{P} 93 \longrightarrow \mathrm{P} 94 \longrightarrow \mathrm{P} 84 \longrightarrow \mathrm{P} 85 \longrightarrow \mathrm{P} 104 \longrightarrow \mathrm{P} 103 \longrightarrow \mathrm{RC} 2 \\
\mathrm{RC} 2 \longrightarrow \mathrm{P} 82 \longrightarrow \mathrm{P} 100 \longrightarrow \mathrm{P} 89 \longrightarrow \mathrm{P} 90 \longrightarrow \mathrm{P} 101 \longrightarrow \mathrm{P} 96 \longrightarrow \mathrm{P} 88 \longrightarrow \mathrm{P} 105 \longrightarrow \mathrm{P} 87 \longrightarrow \mathrm{P} 102 \longrightarrow \mathrm{P} 92 \longrightarrow \mathrm{RC} 2 \\
\mathrm{RC} 2 \longrightarrow \mathrm{P} 91 \longrightarrow \mathrm{P} 86 \longrightarrow \mathrm{P} 106 \longrightarrow \mathrm{P} 83 \longrightarrow \mathrm{RC} 2\end{array}$ \\
\hline RC3 & 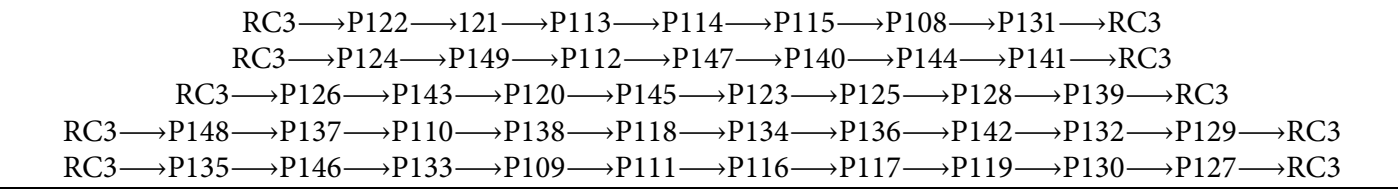 \\
\hline $\mathrm{RC} 4$ & 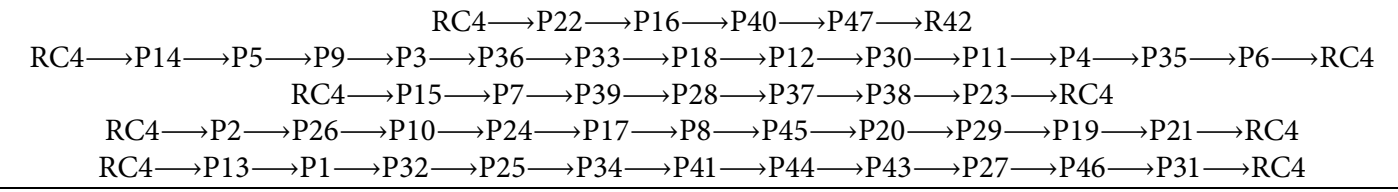 \\
\hline RC5 & $\begin{array}{c}\mathrm{RC5} \longrightarrow \mathrm{P} 52 \longrightarrow \mathrm{P} 49 \longrightarrow \mathrm{P} 58 \longrightarrow \mathrm{P} 66 \longrightarrow \mathrm{P} 79 \longrightarrow \mathrm{P} 57 \longrightarrow \mathrm{P} 68 \longrightarrow \mathrm{P} 50 \longrightarrow \mathrm{P} 53 \longrightarrow \mathrm{P} 51 \longrightarrow \mathrm{P} 55 \longrightarrow \mathrm{P} 71 \longrightarrow \mathrm{RC} 5 \\
\mathrm{RC} 5 \longrightarrow \mathrm{P} 59 \longrightarrow \mathrm{P} 74 \longrightarrow \mathrm{P} 76 \longrightarrow \mathrm{P} 62 \longrightarrow \mathrm{P} 61 \longrightarrow \mathrm{P} 70 \longrightarrow \mathrm{P} 78 \longrightarrow \mathrm{P} 60 \longrightarrow \mathrm{P} 80 \longrightarrow \mathrm{P} 54 \longrightarrow \mathrm{P} 67 \longrightarrow \mathrm{P} 56 \longrightarrow \mathrm{RC} 5 \\
\mathrm{RC} 5 \longrightarrow \mathrm{P} 64 \longrightarrow \mathrm{P} 81 \longrightarrow \mathrm{P} 77 \longrightarrow \mathrm{P} 48 \longrightarrow \mathrm{P} 69 \longrightarrow \mathrm{P} 73 \longrightarrow \mathrm{P} 72 \longrightarrow \mathrm{P} 63 \longrightarrow \mathrm{RC} 5 \\
\mathrm{RC} 5 \longrightarrow \mathrm{P} 75 \longrightarrow \mathrm{P} 65 \longrightarrow \mathrm{RC} 5\end{array}$ \\
\hline
\end{tabular}

Figure 7, wherein $x$ represents the longitude of coordinate, $y$ indicates the latitude of coordinate, and $z$ denotes the mid value of the time window. The optimized vehicle routes with the RS and TWA strategies are shown in Table 8.

Table 8 exhibits that seven vehicles are shared on different routes to serve customers in the multidepot reverse logistics network. For example, vehicle 1 is shared in three routes. One route (e.g., $\mathrm{RC} 1 \longrightarrow \mathrm{P} 128 \longrightarrow \mathrm{P} 138 \longrightarrow \mathrm{P} 7 \longrightarrow \mathrm{P} 69 \longrightarrow \mathrm{P} 78$ $\longrightarrow \mathrm{P} 15 \longrightarrow \mathrm{P} 36 \longrightarrow \mathrm{P} 42 \longrightarrow \mathrm{RC} 1)$ departs from $\mathrm{RC} 1$.
Meanwhile, two routes (e.g., RC3 $\longrightarrow \mathrm{P} 1 \longrightarrow \mathrm{P} 122 \longrightarrow \mathrm{P} 50$ $\longrightarrow \mathrm{P} 95 \longrightarrow \mathrm{P} 109 \longrightarrow \mathrm{P} 51 \longrightarrow \mathrm{P} 41 \longrightarrow \mathrm{P} 129 \longrightarrow \mathrm{P} 13 \longrightarrow$ $\mathrm{P} 166 \longrightarrow \mathrm{P} 158 \longrightarrow \mathrm{RC} 3, \mathrm{RC} 3 \longrightarrow \mathrm{P} 98 \longrightarrow \mathrm{P} 124 \longrightarrow \mathrm{P} 86$ $\longrightarrow \mathrm{P} 112 \longrightarrow \mathrm{P} 82 \longrightarrow \mathrm{P} 136 \longrightarrow \mathrm{P} 28 \longrightarrow \mathrm{P} 137 \longrightarrow \mathrm{P} 113$ $\longrightarrow \mathrm{P} 104 \longrightarrow$ RC3) depart from RC3. Vehicle sharing can improve the resource utilization and operational efficiency of logistics facilities and promote sustainable development among logistics networks. The comparison of results before and after optimization is shown in Table 9 and Figure 8. 
TABLE 6: Parameter values utilized in the computational experiments.

\begin{tabular}{|c|c|}
\hline Notation & Definition \\
\hline$\overline{\beta_{1}}$ & Coefficient of spatial distance \\
\hline$\beta_{2}$ & Coefficient of temporal distance \\
\hline$Q_{s}$ & Maximum capacity of the semitrailer truck \\
\hline$Q_{v}$ & Maximum capacity of vehicle \\
\hline$U_{s}$ & Usage cost of the semitrailer truck (unit: dollar $/ \mathrm{km}$ ) \\
\hline$U_{v}$ & Usage cost of vehicle $v$ (unit: dollar $/ \mathrm{km})$ \\
\hline$M_{s}$ & Annual MC of the semitrailer truck \\
\hline$M_{v}$ & Annual MC of the vehicle \\
\hline$\mu_{e}$ & Penalty cost for early arrival per unit time \\
\hline$\mu_{d}$ & Penalty cost for delayed arrival per unit time \\
\hline$\mu_{a}$ & AC per unit time \\
\hline$W$ & Number of working days in one planning period \\
\hline$B$ & Number of planning periods in one year \\
\hline$F L_{1}$ & Fixed cost of RC1 \\
\hline$F L_{2}$ & Fixed cost of RC2 \\
\hline$F L_{3}$ & Fixed cost of RC3 \\
\hline$F L_{4}$ & Fixed cost of RC4 \\
\hline$F L_{5}$ & Fixed cost of RC5 \\
\hline Pop $_{\text {size }}$ & Population size \\
\hline Nmax & Maximum number of generations runs \\
\hline$R \max$ & Maximum number of runs \\
\hline$s p$ & Selection probability \\
\hline$c p$ & Crossover probability \\
\hline$m p$ & Mutation probability \\
\hline
\end{tabular}

TABLE 7: 3D $k$-means clustering results in MRVRPRSTWA.

\begin{tabular}{lccccc}
\hline Facilities & RC1 & RC2 & RC3 & RC4 & RC5 \\
\hline & & & P1 P2 P4 P6 P10 P13 & P8 P14 P16 P19 P20 & P3 P5 P9 P12 P18 P27 \\
& P7 P15 P39 P42 P48 & P11 P17 P24 P25 P32 & P26 P28 P29 P35 P41 & P21 P22 P23 P31 P37 & P30 P52 P54 P56 P57 \\
& P69 P72 P73 P78 P93 & P34 P53 P91 P92 P97 & P50 P51 P60 P74 P76 & P38 P45 P46 P47 P55 & P58 P64 P65 P75 P77 \\
Pustomers P83 P86 P87 P95 & P59 P63 P68 P80 P84 & P79 P81 P88 P90 P96 \\
& P99 P110 P118 P138 & P102 P133 P135 P146 & P82 P P103 P104 P106 & P85 P89 P94 P114 P123 & P100 P101 P105 P108 \\
& P130 P131 P177 P180 & P148 P160 P183 P115 & P98 P107 P109 P112 P113 & P134 P139 P141 P142 & P111 P125 P127 P140 \\
& P182 P33 P36 P40 P43 & P116 P117 P119 P120 & P121 P122 P124 P129 & P144 P145 P147 P151 & P143 P150 P152 P157 \\
& P44 P49 P126 P128 & P61 P62 P70 P66 P67 & P136 P137 P149 P153 & P155 P161 P165 P168 & P159 P162 P163 P167 \\
& P132 & P71 & P154 P156 P158 P164 & P170 P171 P173 P179 & P169 P172 P174 P175 \\
& & & P166 & P181 & P176 P178 \\
\hline
\end{tabular}

In Table 9 and Figure 8, the total cost is reduced from $\$ 38025$ to $\$ 21373$ in the initial and optimized reverse logistics network on the basis of the RS and TWA strategies in the MRVRPRSTWA. In addition, the TC is decreased from $\$ 4675$ to $\$ 1307$. The sum of the penalty cost and AC after optimization is lower than that before optimization through the TWA strategy. The total number of vehicles is decreased to seven when the vehicles are shared among five RCs.

6.5. Analysis and Discussion. Four cases are considered to verify the applicability of the proposed method in MRVRPRSTWA. In Case 1, each logistics facility operates independently. In Case 2, the RS strategy is considered among logistics facilities. In Case 3, the TWA strategy is adopted among logistics facilities. In Case 4, the RS and TWA strategies are adopted among logistics facilities. The calculation results of the four scenarios are shown in $\mathrm{Ta}$ ble 10 and Figure 9.
In Table 10 and Figure 9, the total cost, violated time, and TNV are significantly reduced in the optimized logistics network with the RS and TWA strategies. TNV in Case 2 is lower than that in Case 1, which shares vehicles among reverse logistics facilities. The violated time is significantly reduced when the TWA strategy is adopted among logistics facilities in Case 3 compared to that of Case 1. The total cost, violated time, and TNV of Case 4 have the minimum value of $\$ 21373,87 \mathrm{~min}$, and 7 , respectively. The total cost, violated time, and TNV are compared in Figure 9. Therefore, the proposed method in MRVRPRSTWA can effectively reallocate resources and improve the operational efficiency.

6.6. Implications. The RS and TWA strategies are considered to optimize recycling service in the multidepot reverse logistics network. The implications obtained from this work are described as follows: 


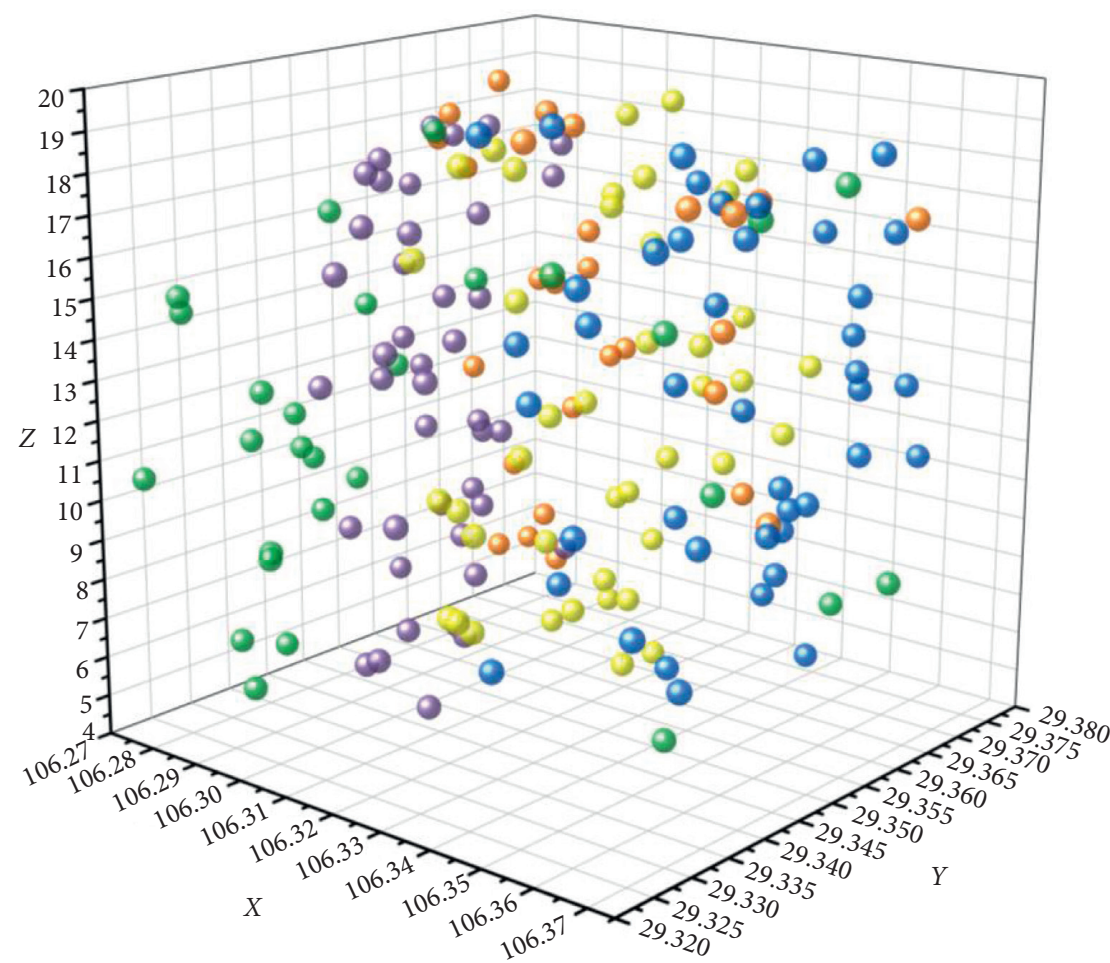

Pickup customers served by RC1

Pickup customers served by RC3

Pickup customers served by RC5
Pickup customers served by RC2

Pickup customers served by RC4

FIgURE 7: Customer clustering results in MRVRPRSTWA.

TABLE 8: Vehicle routes with the RS and TWA strategies.

\begin{tabular}{|c|c|c|}
\hline Vehicles & Facilities & Routes \\
\hline Vehicle 1 & $\begin{array}{l}\mathrm{RC} 1 \\
\mathrm{RC} 3 \\
\mathrm{RC} 3\end{array}$ & $\begin{array}{l}\mathrm{RC1} \longrightarrow \mathrm{P} 128 \longrightarrow \mathrm{P} 138 \longrightarrow \mathrm{P} 7 \longrightarrow \mathrm{P} 69 \longrightarrow \mathrm{P} 78 \longrightarrow \mathrm{P} 15 \longrightarrow \mathrm{P} 36 \longrightarrow \mathrm{P} 42 \longrightarrow \mathrm{RC} 1 \\
\mathrm{RC} 3 \longrightarrow \mathrm{P} 1 \longrightarrow \mathrm{P} 122 \longrightarrow \mathrm{P} 50 \longrightarrow \mathrm{P} 95 \longrightarrow \mathrm{P} 109 \stackrel{\mathrm{P}}{\longrightarrow} \longrightarrow \mathrm{P} 1 \stackrel{\mathrm{P} 41}{\longrightarrow} \longrightarrow \mathrm{P} 129 \stackrel{\mathrm{P} 13 \stackrel{\mathrm{P} 166}{\longrightarrow} \longrightarrow \mathrm{P} 158 \longrightarrow \mathrm{RC} 3}{\longrightarrow} \longrightarrow \mathrm{PC} 3 \longrightarrow \mathrm{P} 98 \longrightarrow \mathrm{P} 124 \longrightarrow \mathrm{P} 86 \longrightarrow \mathrm{P} 112 \longrightarrow \mathrm{P} 82 \longrightarrow \mathrm{P} 136 \longrightarrow \mathrm{P} 28 \longrightarrow \mathrm{P} 137 \longrightarrow \mathrm{P} 113 \longrightarrow \mathrm{P} 104 \longrightarrow \mathrm{RC} 3\end{array}$ \\
\hline Vehicle 2 & $\begin{array}{l}\text { RC2 } \\
\text { RC2 } \\
\text { RC2 }\end{array}$ & 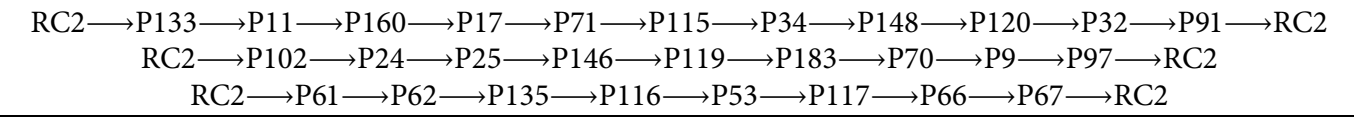 \\
\hline Vehicle 3 & $\begin{array}{l}\text { RC3 } \\
\text { RC4 } \\
\text { RC5 }\end{array}$ & $\begin{array}{l}\mathrm{RC3} \longrightarrow \mathrm{P} 106 \longrightarrow \mathrm{P} 83 \longrightarrow \mathrm{P} 87 \longrightarrow \mathrm{P} 29 \longrightarrow \mathrm{P} 103 \longrightarrow \mathrm{P} 10 \longrightarrow \mathrm{P} 76 \longrightarrow \mathrm{P} 74 \longrightarrow \mathrm{P} 4 \longrightarrow \mathrm{P} 60 \longrightarrow \mathrm{P} 2 \longrightarrow \mathrm{P} 107 \longrightarrow \mathrm{RC} 3 \\
\mathrm{RC} 4 \longrightarrow \mathrm{P} 31 \longrightarrow \mathrm{P} 141 \longrightarrow \mathrm{P} 59 \longrightarrow \mathrm{P} 68 \longrightarrow \mathrm{P} 147 \longrightarrow \mathrm{P} 45 \longrightarrow \mathrm{P} 151 \longrightarrow \mathrm{P} 55 \longrightarrow \mathrm{P} 38 \longrightarrow \mathrm{P} 123 \longrightarrow \mathrm{P} 94 \longrightarrow \mathrm{RC} 4 \\
\mathrm{RC} 5 \longrightarrow \mathrm{P} 154 \longrightarrow \mathrm{P} 26 \longrightarrow \mathrm{P} 121 \longrightarrow \mathrm{P} 35 \longrightarrow \mathrm{P} 176 \longrightarrow \mathrm{P} 175 \longrightarrow \mathrm{P} 90 \longrightarrow \mathrm{P} 179 \longrightarrow \mathrm{P} 172 \longrightarrow \mathrm{RC} 5\end{array}$ \\
\hline Vehicle 4 & $\begin{array}{l}\text { RC4 } \\
\text { RC4 } \\
\text { RC4 }\end{array}$ & $\begin{aligned} \mathrm{RC} 4 \longrightarrow \mathrm{P} 14 \longrightarrow \mathrm{P} 114 \longrightarrow \mathrm{P} 37 \longrightarrow \mathrm{P} 84 \longrightarrow \mathrm{P} 85 \longrightarrow \mathrm{P} 134 \longrightarrow \mathrm{P} 173 \longrightarrow \mathrm{P} 156 \longrightarrow \mathrm{P} 181 \longrightarrow \mathrm{P} 178 \longrightarrow \mathrm{P} 168 \longrightarrow \mathrm{RC} 4 \\
\mathrm{RC} 4 \longrightarrow \mathrm{P} 63 \longrightarrow \mathrm{P} 21 \longrightarrow \mathrm{P} 20 \longrightarrow \mathrm{P} 145 \longrightarrow \mathrm{P} 19 \longrightarrow \mathrm{P} 6 \longrightarrow \mathrm{P} 89 \longrightarrow \mathrm{P} 22 \longrightarrow \mathrm{P} 47 \longrightarrow \mathrm{P} 161 \longrightarrow \mathrm{RC} 4 \\
\mathrm{RC} 4 \longrightarrow \mathrm{P} 144 \longrightarrow \mathrm{P} 165 \longrightarrow \mathrm{P} 8 \longrightarrow \mathrm{P} 46 \longrightarrow \mathrm{P} 139 \longrightarrow \mathrm{P} 142 \longrightarrow \mathrm{P} 16 \longrightarrow \mathrm{P} 80 \longrightarrow \mathrm{P} 155 \longrightarrow \mathrm{P} 23 \longrightarrow \mathrm{RC} 4\end{aligned}$ \\
\hline Vehicle 5 & $\begin{array}{l}\text { RC5 } \\
\text { RC5 }\end{array}$ & $\begin{aligned} & \mathrm{RC} 5 \longrightarrow \mathrm{P} 150 \longrightarrow \mathrm{P} 88 \longrightarrow \mathrm{P} 152 \longrightarrow \mathrm{P} 57 \longrightarrow \mathrm{P} 100 \longrightarrow \mathrm{P} 125 \longrightarrow \mathrm{P} 162 \longrightarrow \mathrm{P} 56 \longrightarrow \mathrm{P} 5 \longrightarrow \mathrm{P} 96 \longrightarrow \mathrm{P} 159 \longrightarrow \mathrm{RC} 5 \\
& \mathrm{RC5} \longrightarrow \mathrm{P} 108 \longrightarrow \mathrm{P} 65 \longrightarrow \mathrm{P} 54 \longrightarrow \mathrm{P} 81 \longrightarrow \mathrm{P} 30 \longrightarrow \mathrm{P} 77 \longrightarrow \mathrm{P} 75 \longrightarrow \mathrm{P} 101 \longrightarrow \mathrm{P} 111 \longrightarrow \mathrm{RC} 5\end{aligned}$ \\
\hline Vehicle 6 & $\begin{array}{l}\mathrm{RC} 1 \\
\mathrm{RC} 1\end{array}$ & $\begin{aligned} \mathrm{RC} 1 \longrightarrow \mathrm{P} 39 \longrightarrow \mathrm{P} 48 \longrightarrow \mathrm{P} 93 \longrightarrow \mathrm{P} 180 \longrightarrow \mathrm{P} 131 \longrightarrow \mathrm{P} 44 \longrightarrow \mathrm{P} 118 \longrightarrow \mathrm{P} 177 \longrightarrow \mathrm{P} 110 \longrightarrow \mathrm{RC} 1 \\
\mathrm{RC} 1 \longrightarrow \mathrm{P} 72 \longrightarrow \mathrm{P} 99 \longrightarrow \mathrm{P} 73 \longrightarrow \mathrm{P} 182 \longrightarrow \mathrm{P} 132 \longrightarrow \mathrm{P} 126 \longrightarrow \mathrm{P} 49 \longrightarrow \mathrm{P} 33 \longrightarrow \mathrm{P} 130 \longrightarrow \mathrm{P} 43 \longrightarrow \mathrm{P} 40 \longrightarrow \mathrm{RC} 1\end{aligned}$ \\
\hline Vehicle 7 & $\begin{array}{l}\text { RC5 } \\
\text { RC5 }\end{array}$ & $\begin{array}{l}\mathrm{RC} 5 \longrightarrow \mathrm{P} 3 \longrightarrow \mathrm{P} 169 \longrightarrow \mathrm{P} 140 \longrightarrow \mathrm{P} 9 \longrightarrow \mathrm{P} 153 \longrightarrow \mathrm{P} 167 \longrightarrow \mathrm{P} 164 \longrightarrow \mathrm{P} 52 \longrightarrow \mathrm{P} 171 \longrightarrow \mathrm{P} 170 \longrightarrow \mathrm{P} 174 \longrightarrow \mathrm{RC} 5 \\
\mathrm{RC} 5 \longrightarrow \mathrm{P} 105 \longrightarrow \mathrm{P} 79 \longrightarrow \mathrm{P} 18 \longrightarrow \mathrm{P} 12 \longrightarrow \mathrm{P} 58 \longrightarrow \mathrm{P} 157 \longrightarrow \mathrm{P} 163 \longrightarrow \mathrm{P} 64 \longrightarrow \mathrm{P} 143 \longrightarrow \mathrm{P} 27 \longrightarrow \mathrm{P} 127 \longrightarrow \mathrm{RC} 5\end{array}$ \\
\hline
\end{tabular}

TABLE 9: Comparison of the results before and after optimization.

\begin{tabular}{|c|c|c|c|c|c|c|c|}
\hline Scenarios & $\begin{array}{c}\text { Transportation cost } \\
(\$)\end{array}$ & $\begin{array}{c}\text { Penalty cost } \\
(\$)\end{array}$ & $\begin{array}{c}\text { Assignment cost } \\
(\$)\end{array}$ & $\begin{array}{c}\text { Fixed cost } \\
(\$)\end{array}$ & $\begin{array}{c}\text { Number of } \\
\text { semitrailer trucks }\end{array}$ & $\begin{array}{c}\text { Number of } \\
\text { vehicles }\end{array}$ & $\begin{array}{c}\text { Total cost } \\
(\$)\end{array}$ \\
\hline $\begin{array}{l}\text { Before } \\
\text { optimization }\end{array}$ & 4675 & 6000 & - & 6350 & - & 21 & 38025 \\
\hline $\begin{array}{l}\text { After } \\
\text { optimization }\end{array}$ & 1307 & 1566 & 2150 & 6350 & 2 & 7 & 21373 \\
\hline
\end{tabular}




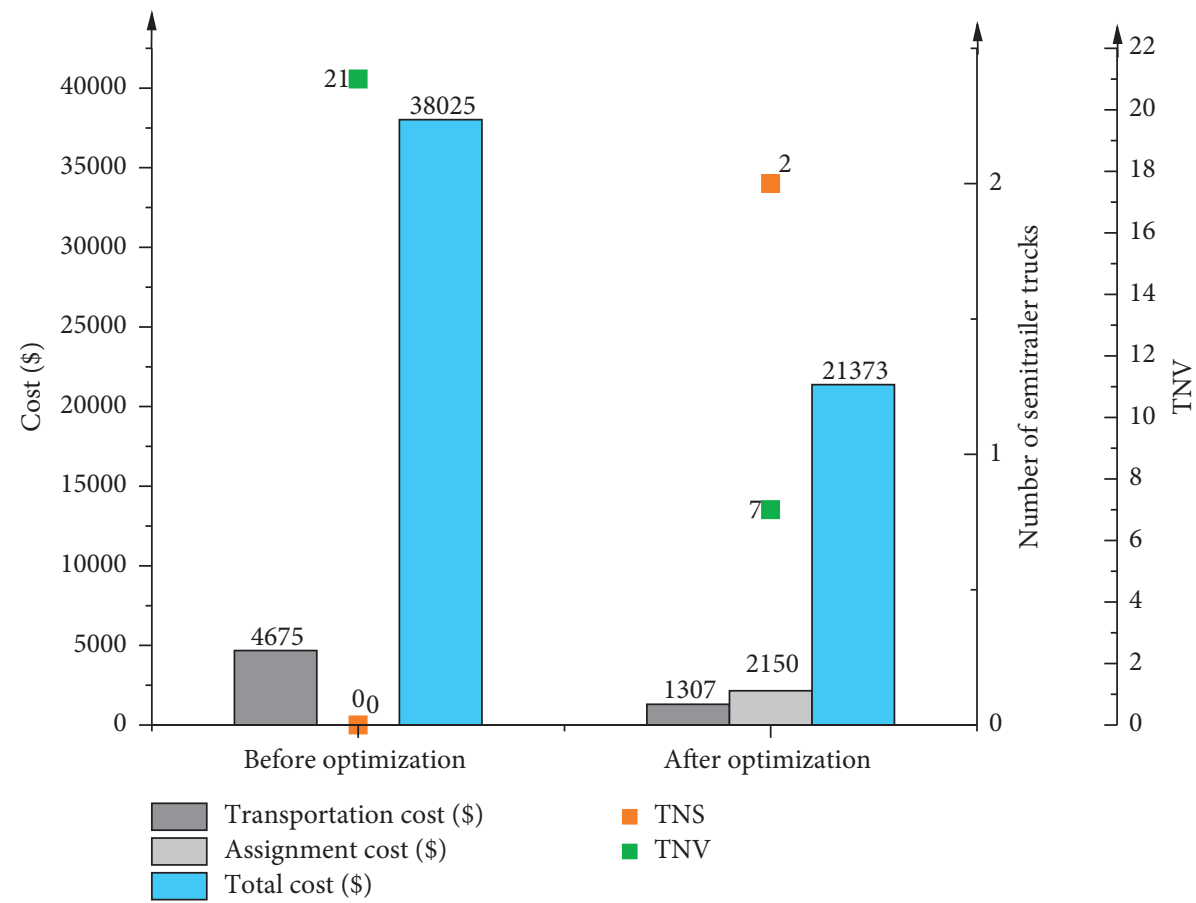

FIGURE 8: Comparison of the results before and after optimization.

TABLE 10: Comparison of the optimization results of the four scenarios.

Scenarios The total cost (\$) Violated time (min) Assigned time (min) The number of semitrailer trucks The number of vehicles

Case $1 \quad 38025$

Case 2

27939

Case 3

32616

333

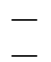

Case 4

$107 \quad 247$

-
2
2

87

215

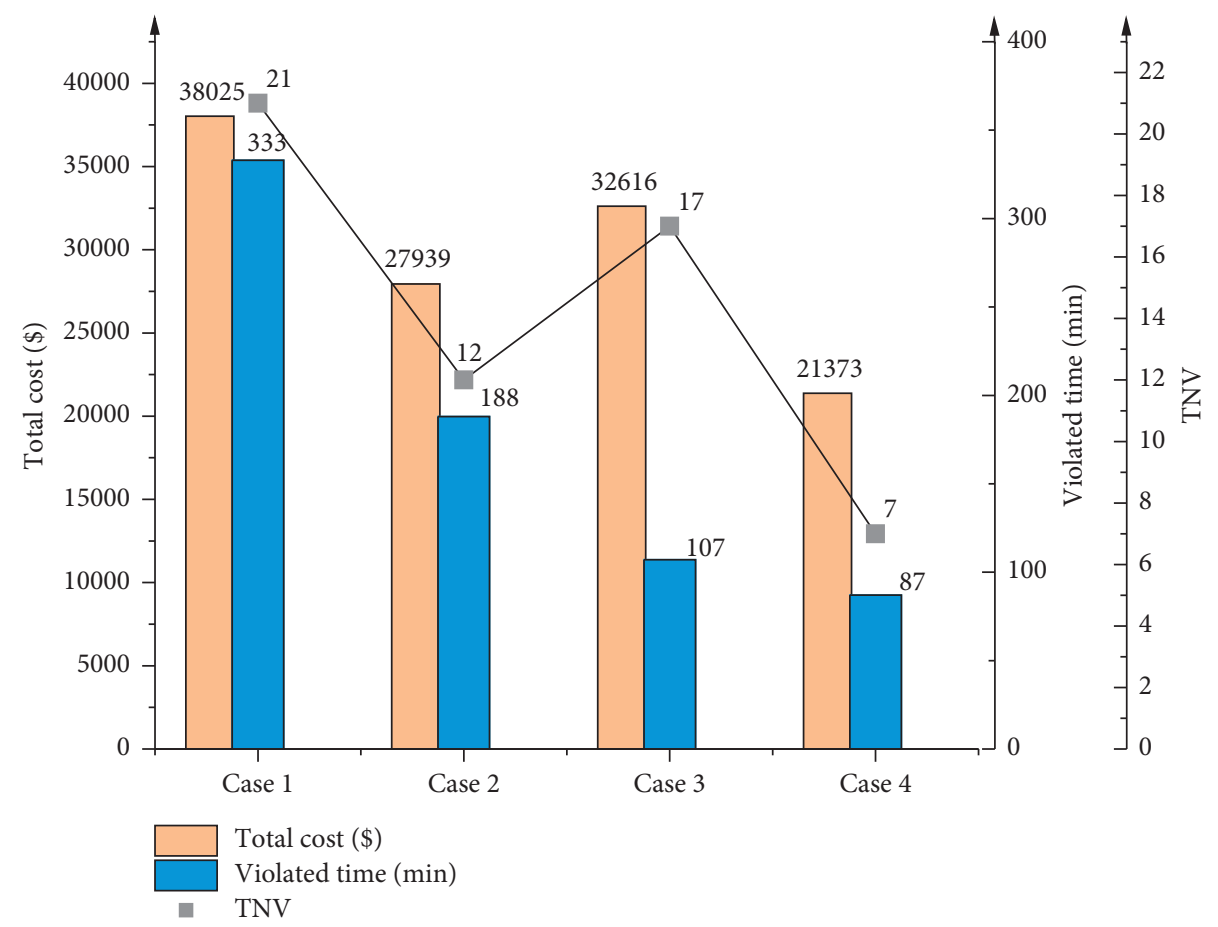

Figure 9: Comparison of the total cost, violated time, and TNV. 
(1) The RS strategy contributes to the resource utilization of reverse logistics network and promotes the sustainable development of the intelligent logistics system. Vehicles often serve customers on one route in a working period, thereby resulting in low vehicle utilization. Vehicles serve customers on several routes in a working period based on satisfying customer service time window with the adoption of the RS strategy. This strategy shares the resources within and between logistics facilities to obtain the maximum resource utilization in MRVRPRSTWA.

(2) The TWA strategy can enhance the operational efficiency of logistics networks. The candidate time windows of customers with high penalty costs on account of the violation of time windows are assigned to corresponding customers through the TWA strategy to achieve the maximum operational efficiency in MRVRPRSTWA. The TWA strategy is of great theoretical and practical significance to the sustainable development of reverse logistics networks.

(3) The RS and TWA strategies in reverse logistics network can reduce the negative impact of logistics enterprises on the environment, optimize resource allocation, maximize benefits, promote the development of green logistics, and provide related development decisions for logistics enterprises and government departments. The established mathematical model and the hybrid heuristic algorithm can also provide a reliable reference for the applicability and effectiveness of the RS and TWA strategies in addressing MRVRPRSTWA.

\section{Conclusions}

This work studies the RS and TWA strategies in multidepot recycling logistics networks. The RS strategy can effectively improve resource utilization and optimize resource configuration in logistics networks. A bi-objective optimization model is proposed for MRVRPRSTWA with the minimum operating cost and TNV. A hybrid heuristic algorithm, which includes 3D $k$-means clustering algorithm and NSGA-II algorithm, is also designed to address MRVRPRSTWA. The 3D $k$-means clustering algorithm is used to cluster customers in the first step of the hybrid heuristic algorithm for reducing the computational complexity of multidepot vehicle routing problem. Next, the NSGA-II algorithm is used to find the optimal vehicle routes and assign candidate time windows to customers.

A real-world case study in Chongqing City, China, is analyzed to verify the performance of the proposed mathematical model and the hybrid heuristic algorithm in MRVRPRSTWA. The computational results demonstrate that the total operating cost and TNV can be decreased through the proposed method. The total operating cost is reduced from $\$ 38025$ to $\$ 21373$, and TNV is minimized from 21 to 7 . The comparison of the performance of three algorithms shows that the NSGA-II has a better performance in solving MRVRPRSTWA than MOEA and MOPSO. Four different scenarios with and without RS and TWA strategies are presented to demonstrate the applicability of the proposed method. The results of four scenarios indicate that the operational efficiency of the logistics network can be improved via the RS and TWA strategies.

In this study, the RS and TWA strategies are encouraged to promote the sustainable development of multidepot logistics network. On the one hand, the RS strategy among logistics facilities can optimize the resource configuration and enhance the resource utilization. On the other hand, the TWA strategy can improve the operational efficiency of logistics network by assigning candidate time windows to customers. Although only the RS and TWA strategies can improve the operational efficiency of logistics network to a certain extent, the greatest benefits can be obtained by simultaneously adopting both, which is demonstrated in section 6.5. The RS and TWA strategies can be used as references when policy-makers make decisions for logistics development.

Many research questions can be studied in the future on the basis of this work. (1) Delivery activity can be considered on the basis of the MRVRPRSTWA to construct pickup and delivery logistics network. (2) The proposed algorithm can be combined with exact algorithms to enhance the accuracy and efficiency of computation. (3) Collaboration among logistics facilities and profit allocation mechanism can be investigated on the MRVRPRSTWA. (4) The environmental impact in the MRVRPRSTWA can be explored in the future.

\section{Data Availability}

The vehicle routing data used to support the findings of this study are included within the article.

\section{Conflicts of Interest}

The authors declare no conflicts of interest.

\section{Acknowledgments}

This research was supported by the National Natural Science Foundation of China (Grant Nos. 71871035 and 41977337), Humanity and Social Science Youth Foundation of Ministry of Education of China (Grant No. 18YJC630189), Key Science and Technology Research Project of Chongqing $\mathrm{Mu}-$ nicipal Education Commission (Grant No. KJZDK202000702), Key Project of Human Social Science of Chongqing Municipal Education Commission (Grant No. 20SKGH079), Social Science Foundation of Chongqing of China (Grant No. 2019YBGL054), and Chongqing Graduate Tutor Team Construction Project (Grant No. JDDSTD2019008). This research was also supported by 2018 Chongqing Liuchuang Plan Innovation Project (Grant No. cx2018111). 


\section{References}

[1] T. R. P. Ramos, M. I. Gomes, and A. P. Barbosa-Póvoa, "Planning a sustainable reverse logistics system: balancing costs with environmental and social concerns," Omega, vol. 48, pp. 60-74, 2014.

[2] M. Mojtahedi, A. M. Fathollahi-Fard, R. Tavakkoli-Moghaddam, and S. Newton, "Sustainable vehicle routing problem for coordinated solid waste management," Journal of Industrial Information Integration, vol. 23, p. 100220, 2021.

[3] Z. Xiao, J. Sun, W. Shu, and T. Wang, "Location-allocation problem of reverse logistics for end-of-life vehicles based on the measurement of carbon emissions," Computers \& Industrial Engineering, vol. 127, pp. 169-181, 2019.

[4] T.-Y. Liao, "Reverse logistics network design for product recovery and remanufacturing," Applied Mathematical Modelling, vol. 60, pp. 145-163, 2018.

[5] M. Rahimi and V. Ghezavati, "Sustainable multi-period reverse logistics network design and planning under uncertainty utilizing conditional value at risk $(\mathrm{CVaR})$ for recycling construction and demolition waste," Journal of Cleaner Production, vol. 172, pp. 1567-1581, 2018.

[6] J. Trochu, A. Chaabane, and M. Ouhimmou, "A two-stage stochastic optimization model for reverse logistics network design under dynamic suppliers' locations," Waste Management, vol. 95, pp. 569-583, 2019.

[7] Z. Yang, L. Guo, and Z. Yang, "Emergency logistics for wildfire suppression based on forecasted disaster evolution," Annals of Operations Research, vol. 283, no. 1-2, pp. 917-937, 2017.

[8] Y. Wang, Q. Li, X. Guan, M. Xu, Y. Liu, and H. Wang, "Twoechelon collaborative multi-depot multi-period vehicle routing problem," Expert Systems with Applications, vol. 167, p. 114201, 2021.

[9] J. Li, Y. Li, and P. M. Pardalos, "Multi-depot vehicle routing problem with time windows under shared depot resources," Journal of Combinatorial Optimization, vol. 31, no. 2, pp. 515-532, 2016.

[10] Y. Wang, J. Zhang, K. Assogba, Y. Liu, M. Xu, and Y. Wang, "Collaboration and transportation resource sharing in multiple centers vehicle routing optimization with delivery and pickup," Knowledge-Based Systems, vol. 160, pp. 296-310, 2018.

[11] J. Li, R. Wang, T. Li, Z. Lu, and P. M. Pardalos, "Benefit analysis of shared depot resources for multi-depot vehicle routing problem with fuel consumption," Transportation Research Part D: Transport and Environment, vol. 59, pp. 417-432, 2018.

[12] Y.-J. Gong, J. Zhang, O. Liu, R.-Z. Huang, H. S.-H. Chung, and Y.-H. Shi, "Optimizing the vehicle routing problem with time windows: a discrete particle swarm optimization approach," IEEE Transactions on Systems, Man, and Cybernetics, Part C (Applications and Reviews), vol. 42, no. 2, pp. 254-267, 2012.

[13] İ. Küçükoğlu and N. Öztürk, "A differential evolution approach for the vehicle routing problem with backhauls and time windows," Journal of Advanced Transportation, vol. 48, no. 8, pp. 942-956, 2014.

[14] D. Taş, O. Jabali, and T. Van Woensel, "A vehicle routing problem with flexible time windows," Computers \& Operations Research, vol. 52, pp. 39-54, 2014.

[15] Z. Miao, F. Yang, K. Fu, and D. Xu, "Transshipment service through crossdocks with both soft and hard time windows," Annals of Operations Research, vol. 192, no. 1, pp. 21-47, 2010.
[16] S. Iqbal, M. Kaykobad, and M. S. Rahman, "Solving the multiobjective vehicle routing problem with soft time windows with the help of bees," Swarm and Evolutionary Computation, vol. 24, pp. 50-64, 2015.

[17] S. Mouthuy, F. Massen, Y. Deville, and P. Van Hentenryck, "A multistage very large-scale neighborhood search for the vehicle routing problem with soft time windows," Transportation Science, vol. 49, no. 2, pp. 223-238, 2015.

[18] R. Spliet and G. Desaulniers, "The discrete time window assignment vehicle routing problem," European Journal of Operational Research, vol. 244, no. 2, pp. 379-391, 2015.

[19] S. Martins, M. Ostermeier, P. Amorim, A. Hübner, and B. Almada-Lobo, "Product-oriented time window assignment for a multi-compartment vehicle routing problem," European Journal of Operational Research, vol. 276, no. 3, pp. 893-909, 2019.

[20] A. Mihi Ramírez, "Product return and logistics knowledge: influence on performance of the firm," Transportation Research Part E: Logistics and Transportation Review, vol. 48, no. 6, pp. 1137-1151, 2012.

[21] N. Aras, D. Aksen, and M. Tuğrul Tekin, "Selective multidepot vehicle routing problem with pricing," Transportation Research Part C: Emerging Technologies, vol. 19, no. 5, pp. 866-884, 2011.

[22] P. He, S. Zhang, and C. He, "Impacts of logistics resource sharing on B2C E-commerce companies and customers," Electronic Commerce Research and Applications, vol. 34, p. 100820, 2019.

[23] R. Spliet and A. F. Gabor, "The time window assignment vehicle routing problem," Transportation Science, vol. 49, no. 4, pp. 721-731, 2015.

[24] W. Wilcox, P. A. Horvath, S. E. Griffis, and C. W. Autry, “A Markov model of liquidity effects in reverse logistics processes: the effects of random volume and passage," International Journal of Production Economics, vol. 129, no. 1, pp. 86-101, 2011.

[25] M. M. Veiga, "Analysis of efficiency of waste reverse logistics for recycling," Waste Management \& Research, vol. 31, no. 10_ suppl, pp. 26-34, 2013.

[26] A. El korchi and D. Millet, "Designing a sustainable reverse logistics channel: the 18 generic structures framework," Journal of Cleaner Production, vol. 19, no. 6-7, pp. 588-597, 2011.

[27] F. T. S. Chan, H. K. Chan, and V. Jain, "A framework of reverse logistics for the automobile industry," International Journal of Production Research, vol. 50, no. 5, pp. 1318-1331, 2012.

[28] C. Bai and J. Sarkis, "Flexibility in reverse logistics: a framework and evaluation approach," Journal of Cleaner Production, vol. 47, pp. 306-318, 2013.

[29] E. Roghanian and P. Pazhoheshfar, "An optimization model for reverse logistics network under stochastic environment by using genetic algorithm," Journal of Manufacturing Systems, vol. 33, no. 3, pp. 348-356, 2014.

[30] M. N. Shaik and W. Abdul-Kader, "A hybrid multiple criteria decision making approach for measuring comprehensive performance of reverse logistics enterprises," Computers \& Industrial Engineering, vol. 123, pp. 9-25, 2018.

[31] X. Wang, H. Wang, X. Zhang, Z. Feng, and J. Wu, "Stochastic seat allocation models for passenger rail transportation under customer choice," Transportation Research Part E: Logistics and Transportation Review, vol. 96, pp. 95-112, 2016.

[32] Y. Wang, K. Assogba, J. Fan, M. Xu, Y. Liu, and H. Wang, "Multi-depot green vehicle routing problem with shared transportation resource: integration of time-dependent speed 
and piecewise penalty cost," Journal of Cleaner Production, vol. 232, pp. 12-29, 2019.

[33] X. Xu, J. Hao, and Y. Zheng, "Multi-objective artificial bee colony algorithm for multi-stage resource leveling problem in sharing logistics network," Computers \& Industrial Engineering, vol. 142, p. 106338, 2020.

[34] Q. An, Y. Wen, T. Ding, and Y. Li, "Resource sharing and payoff allocation in a three-stage system: integrating network DEA with the Shapley value method," Omega, vol. 85, pp. 16-25, 2019.

[35] L. Sun, S. Wang, S. Liu, L. Yao, W. Luo, and A. Shukla, “A completive research on the feasibility and adaptation of shared transportation in mega-cities-a case study in Beijing," Applied Energy, vol. 230, pp. 1014-1033, 2018.

[36] C. L. Quintero-Araujo, A. Gruler, A. A. Juan, and J. Faulin, "Using horizontal cooperation concepts in integrated routing and facility-location decisions," International Transactions in Operational Research, vol. 26, no. 2, pp. 551-576, 2019.

[37] Y. Wang, J. Zhang, X. Guan, M. Xu, Z. Wang, and H. Wang, "Collaborative multiple centers fresh logistics distribution network optimization with resource sharing and temperature control constraints," Expert Systems with Applications, vol. 165 , p. 113838, 2021.

[38] J. C. Molina, J. L. Salmeron, I. Eguia, and J. Racero, "The heterogeneous vehicle routing problem with time windows and a limited number of resources," Engineering Applications of Artificial Intelligence, vol. 94, p. 103745, 2020.

[39] Y. Wang, Q. Li, X. Guan, J. Fan, Y. Liu, and H. Wang, "Collaboration and resource sharing in the multidepot multiperiod vehicle routing problem with pickups and deliveries," Sustainability, vol. 12, no. 15, p. 5966, 2020.

[40] D. Dechampai, L. Tanwanichkul, K. Sethanan, and R. Pitakaso, "A differential evolution algorithm for the capacitated VRP with flexibility of mixing pickup and delivery services and the maximum duration of a route in poultry industry," Journal of Intelligent Manufacturing, vol. 28, no. 6, pp. 1357-1376, 2015.

[41] H. Xu, P. Pu, and F. Duan, "A hybrid ant colony optimization for dynamic multidepot vehicle routing problem," Discrete Dynamics in Nature and Society, vol. 2018, pp. 1-10, 2018.

[42] J. N. Min, C. Jin, and L. J. Lu, "Maximum-minimum distance clustering method for split-delivery vehicle-routing problem: case studies and performance comparisons," Advances in Production Engineering \& Management, vol. 14, no. 1, pp. 125-135, 2019.

[43] X. Ge, G. Xue, and P. Wen, "Proactive two-level dynamic distribution routing optimization based on historical data," Mathematical Problems in Engineering, vol. 2018, Article ID 5191637, 15 pages, 2018.

[44] H. Fan, Y. Zhang, P. Tian, Y. Lv, and H. Fan, "Time-dependent multi-depot green vehicle routing problem with time windows considering temporal-spatial distance," Computers \& Operations Research, vol. 129, p. 105211, 2021.

[45] D. Liu, Z. Deng, X. Mao, Y. Yang, and E. I. Kaisar, "TwoEchelon vehicle-routing problem: optimization of autonomous delivery vehicle-assisted E-grocery distribution," IEEE Access, vol. 8, pp. 108705-108719, 2020.

[46] V. Hemmelmayr, K. F. Doerner, R. F. Hartl, and S. Rath, “A heuristic solution method for node routing based solid waste collection problems," Journal of Heuristics, vol. 19, no. 2, pp. 129-156, 2011.

[47] R. Alizadeh Foroutan, J. Rezaeian, and I. Mahdavi, "Green vehicle routing and scheduling problem with heterogeneous fleet including reverse logistics in the form of collecting returned goods," Applied Soft Computing, vol. 94, p. 106462, 2020.

[48] A. Parchami Afra and J. Behnamian, "Lagrangian heuristic algorithm for green multi-product production routing problem with reverse logistics and remanufacturing," Journal of Manufacturing Systems, vol. 58, pp. 33-43, 2021.

[49] H. Kim, J. Yang, and K.-D. Lee, "Reverse logistics using a multi-depot VRP approach for recycling end-of-life consumer electronic products in South Korea," International Journal of Sustainable Transportation, vol. 5, no. 5, pp. 289-318, 2011.

[50] J. Liu and Y. He, "A clustering-based multiple ant colony system for the waste collection vehicle routing problems," in Proceedings of 2012 Fifth International Symposium on Computational Intelligence and Design, Washington, DC, USA, October 2012.

[51] T. R. P. Ramos and R. C. Oliveira, "Delimitation of service areas in reverse logistics networks with multiple depots," Journal of the Operational Research Society, vol. 62, no. 7, pp. 1198-1210, 2017.

[52] K. Govindan, H. Mina, A. Esmaeili, and S. M. GholamiZanjani, "An integrated hybrid approach for circular supplier selection and closed loop supply chain network design under uncertainty," Journal of Cleaner Production, vol. 242, p. 118317, 2020.

[53] K. Dalmeijer and R. Spliet, "A branch-and-cut algorithm for the time window assignment vehicle routing problem," Computers \& Operations Research, vol. 89, pp. 140-152, 2018.

[54] Y. Wang, S. Zhang, X. Guan et al., "Collaborative multi-depot logistics network design with time window assignment," Expert Systems with Applications, vol. 140, p. 112910, 2020.

[55] A. Subramanyam, A. Wang, and C. E. Gounaris, "A scenario decomposition algorithm for strategic time window assignment vehicle routing problems," Transportation Research Part B: Methodological, vol. 117, pp. 296-317, 2018.

[56] F. Neves-Moreira, D. Pereira da Silva, L. Guimarães, P. Amorim, and B. Almada-Lobo, "The time window assignment vehicle routing problem with product dependent deliveries," Transportation Research Part E: Logistics and Transportation Review, vol. 116, pp. 163-183, 2018.

[57] M. Jalilvand, M. Bashiri, and E. Nikzad, "An effective Progressive Hedging algorithm for the two-layers time window assignment vehicle routing problem in a stochastic environment," Expert Systems with Applications, vol. 165, p. 113877, 2021.

[58] G. Xu, M. Xu, Y. Wang, Y. Liu, Q. Lv, and E. Osaba, "Collaborative multidepot petrol station replenishment problem with multicompartments and time window assignment," Journal of Advanced Transportation, vol. 2020, Article ID 8843397, 22 pages, 2020.

[59] D. K. Jana and B. Das, "A two-storage multi-item inventory model with hybrid number and nested price discount via hybrid heuristic algorithm," Annals of Operations Research, vol. 248, no. 1-2, pp. 281-304, 2016.

[60] Z. Xiong, X.-H. Li, J.-C. Liang, and L.-J. Li, "A multi-objective hybrid algorithm for optimization of grid structures," International Journal of Applied Mechanics, vol. 10, no. 1, p. $1850009,2018$.

[61] X. Sun, S. Guo, J. Guo, and B. Du, “A hybrid multi-objective evolutionary algorithm with heuristic adjustment strategies and variable neighbor-hood search for flexible job-shop scheduling problem considering flexible rest time," IEEE Access, vol. 7, pp. 157003-157018, 2019.

[62] J. Li, P. M. Pardalos, H. Sun, J. Pei, and Y. Zhang, "Iterated local search embedded adaptive neighborhood selection approach for the multi-depot vehicle routing problem with 
simultaneous deliveries and pickups," Expert Systems with Applications, vol. 42, no. 7, pp. 3551-3561, 2015.

[63] D. Cinar, K. Gakis, and P. M. Pardalos, "A 2-phase constructive algorithm for cumulative vehicle routing problems with limited duration," Expert Systems with Applications, vol. 56, pp. 48-58, 2016.

[64] S. Gao, Y. Wang, J. Cheng, Y. Inazumi, and Z. Tang, "Ant colony optimization with clustering for solving the dynamic location routing problem," Applied Mathematics and Computation, vol. 285, pp. 149-173, 2016.

[65] Y. Wang, Y. Yuan, K. Assogba et al., "Design and profit allocation in two-echelon heterogeneous cooperative logistics network optimization," Journal of Advanced Transportation, vol. 2018, Article ID 4607493, 20 pages, 2018.

[66] Y. Wang, X. Ma, Z. Li, Y. Liu, M. Xu, and Y. Wang, "Profit distribution in collaborative multiple centers vehicle routing problem," Journal of Cleaner Production, vol. 144, pp. 203219, 2017.

[67] M. Rashidnejad, S. Ebrahimnejad, and J. Safari, "A bi-objective model of preventive maintenance planning in distributed systems considering vehicle routing problem," Computers \& Industrial Engineering, vol. 120, pp. 360-381, 2018.

[68] Y. Wang, C. Li, X. Jin, Y. Xiang, and X. Li, "Multi-objective optimization of rolling schedule for tandem cold strip rolling based on NSGA-II," Journal of Manufacturing Processes, vol. 60, pp. 257-267, 2020.

[69] Y. Wang, Y. Yuan, X. Guan, H. Wang, Y. Liu, and M. Xu, "Collaborative mechanism for pickup and delivery problems with heterogeneous vehicles under time windows," Sustainability, vol. 11, no. 12, 2019.

[70] Y. Wang, Y. Yuan, X. Guan et al., "Collaborative two-echelon multicenter vehicle routing optimization based on statespace-time network representation," Journal of Cleaner Production, vol. 258, p. 120590, 2020.

[71] Y. Wang, S. Peng, X. Zhou, M. Mahmoudi, and L. Zhen, "Green logistics location-routing problem with eco-packages," Transportation Research Part E: Logistics and Transportation Review, vol. 143, p. 102118, 2020.

[72] B. Li, J. Li, K. Tang, and X. Yao, "Many-objective evolutionary algorithms," ACM Computing Surveys, vol. 48, no. 1, pp. 1-35, 2015.

[73] A. Ameli, S. Bahrami, F. Khazaeli, and M.-R. Haghifam, "A multiobjective particle swarm optimization for sizing and placement of DGs from DG owner's and distribution company's viewpoints," IEEE Transactions on Power Delivery, vol. 29, no. 4, pp. 1831-1840, 2014. 